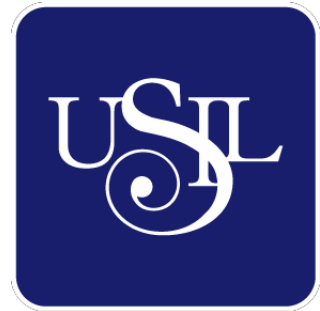

UNIVERSIDAD

SAN IGNACIO

DE LOYOLA

FACULTAD DE CIENCIAS EMPRESARIALES

Carrera de Marketing

\title{
RELACIÓN ENTRE EL MODELO BIG FIVE DE PERSONALIDAD Y LAS PREFERENCIAS MUSICALES DE ADULTOS RESIDENTES EN LIMA
}

Tesis para optar el Título Profesional de Licenciado en Marketing

GONZALO ANDRE PALOMINO GAMARRA

LUCY TAMARIZ UBILLUS

Asesor:

Jaime Briceño Morales

Lima - Perú

2019 


\title{
DEDICATORIA:
}

\begin{abstract}
A mi padre
Armando Tamariz Vega, pues fue el principal cimiento para la construcción de mi vida profesional, sentó en mí las bases de responsabilidad y deseos de superación. En él tengo el espejo en el cual me quiero reflejar pues sus virtudes finitas y gran corazón llevaron admirarlo cuando estuvo en vida y hoy más que nunca.

Lucy.
\end{abstract}

\section{A mis padres y hermanos}

El presente trabajo de investigación se lo dedicó a mi familia Palomino Gamarra, quienes han sido la base de mi formación, cada uno de ustedes aportando grandes cosas a mi vida y ayudándome a enfrentar cada tarea en este camino. Les agradezco por todo, en especial por ser los principales benefactores del desarrollo de mi tesis.

Gonzalo. 


\section{Resumen}

Uno de los modelos más difundidos que pretende describir la personalidad es el Big Five (o cinco grandes). En investigaciones internacionales, los componentes de dicho modelo han sido correlacionados con las preferencias musicales. En el contexto peruano, no existe una investigación que vincule ambas variables. Es por ello que, la investigación recopiló datos de 384 adultos residentes en Lima Metropolitana a través de un formulario de Google. Las preferencias musicales fueron extraídas de GFK y contrastada con la opinión de un experto del sector; mientras que para el modelo Big Five fue empleada la versión de 15 preguntas (la versión más corta hasta el momento) a fin de incrementar la probabilidad de obtener una respuesta. Los resultados evidenciaron que tres componentes de la personalidad tienen correlación con las preferencias musicales: simpatía, extroversión y apertura.

Keywords: Personalidad, Big Five, Preferencias musicales, Residentes limeños 


\section{Introducción}

"La música es el reflejo del alma" es una frase que comúnmente se escucha, pero hasta ahora el alma solo ha sido objeto de aproximaciones filosóficas y religiosas. A diferencia del alma, la personalidad sí ha sido estudiada con rigor científico. Múltiples esfuerzos han sido realizados para dimensionar la personalidad. Uno de los modelos de mayor difusión académica es el conocido Big Five. Por otro lado, las preferencias musicales han sido objeto de estudio en distintos ámbitos, algunas publicaciones realizadas en journals especializados han correlacionado éstas y los componentes de la personalidad.

Y es que resulta tentador plantear una relación entre las preferencias musicales y la personalidad. En el campo interdisciplinario del marketing y la psicología a menudo se busca determinar si existe relación entre la personalidad y los patrones de consumo con múltiples fines: lanzar un nuevo producto, incrementar el consumo que ya existe, segmentar a los clientes, entre otros.

Lima es la ciudad más poblada del país, por tanto, es un segmento considerable a estudiar debido a que tiene una proporción considerable de población peruana. Debe considerarse además que, la demanda de música naturalmente se concentra en dicha ciudad. Cabe mencionar que, los estudios de preferencias musicales de GFK fueron realizados en una población mayor de edad.

En los años noventa, el contenido musical era comercializado a través de cintas magnéticas de audio y discos compactos. Con el nuevo milenio, los primeros dispositivos electrónicos de almacenamiento asumieron un rol más protagónico. El internet, en los últimos años, ha terminado por facilitar a los ciudadanos de Lima y otras urbes del país el acceso a música de todas partes del mundo. Incluso, existen grupos de jovencitas que admiran a grupos de un país tan lejano como Corea del Sur. Ello, no hubiera sido posible si es que el acceso a la música no se hubiera democratizado.

Por todo lo anteriormente mencionado, la investigación ha sido orientada a determinar si existe relación entre los componentes del Modelo Big Five de Personalidad y las preferencias musicales en el caso de adultos residentes en Lima. El tema, naturalmente, será abordado desde una perspectiva propia del marketing. 
Contenido

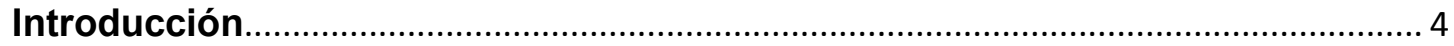

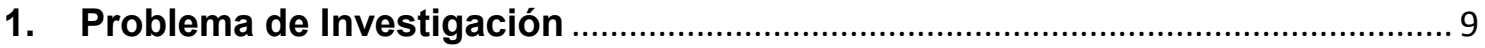

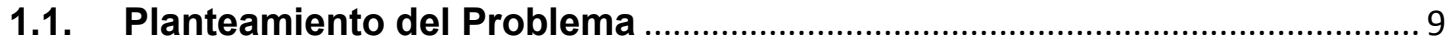

1.2. Formulación del Problema ........................................................................... 12

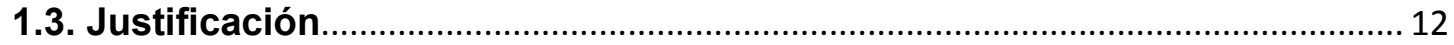

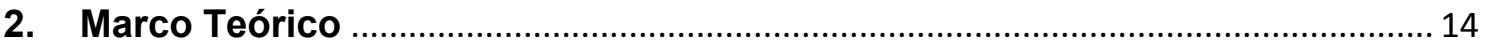

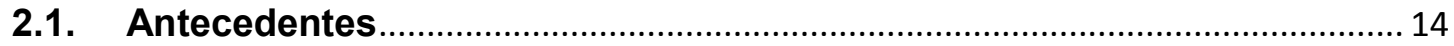

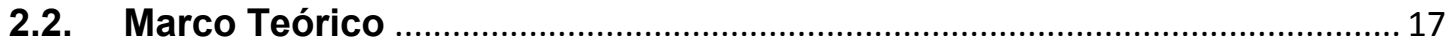

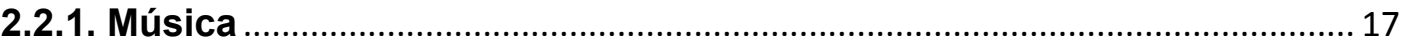

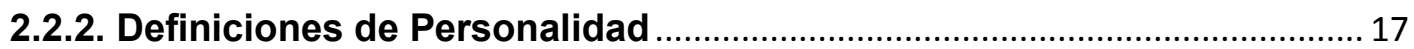

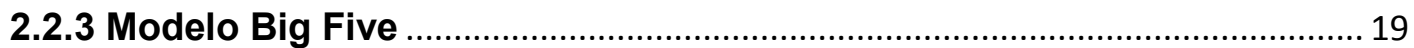

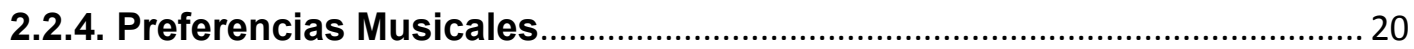

2.2.5. Música y su relación con la personalidad ................................................ 23

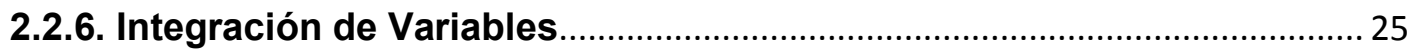

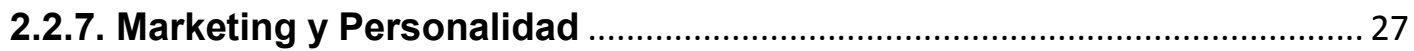

2.2.8. Enfoque moderno de la medición de la personalidad............................... 28

2.2.9. Razones para usar el marketing de personalidad y los aspectos éticos

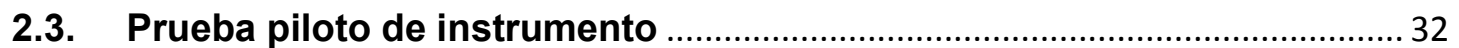

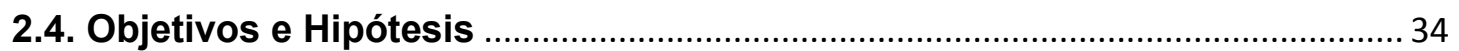

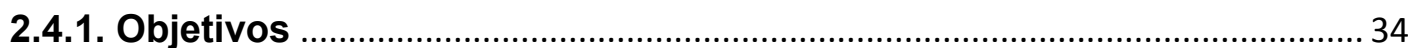

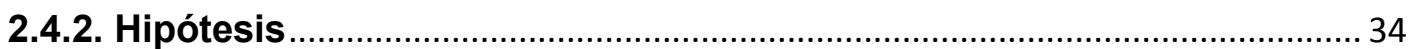

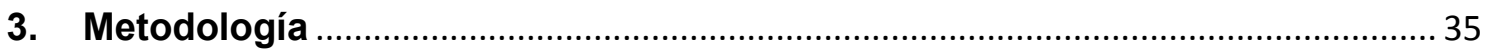

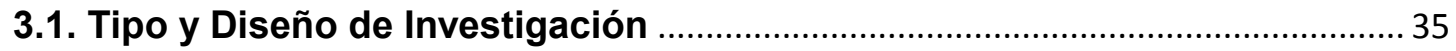

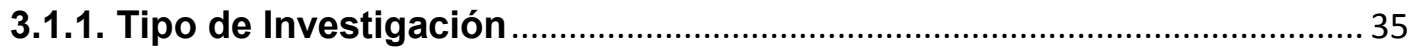

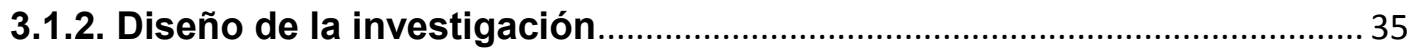

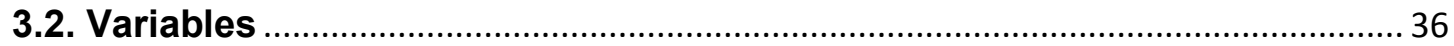

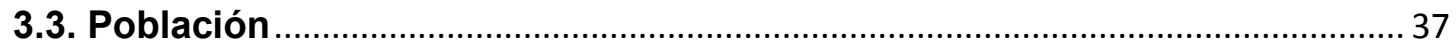

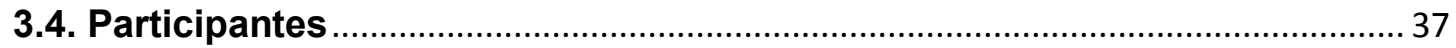

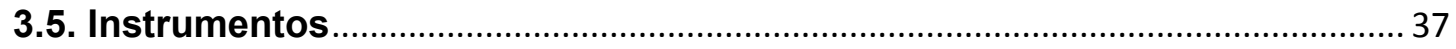

3.5.1. Cuestionario Big Five - Versión Extra Corta (Extra Short) ...................... 37

3.5.2. Cuestionario sobre las presencias musicales ......................................... 38

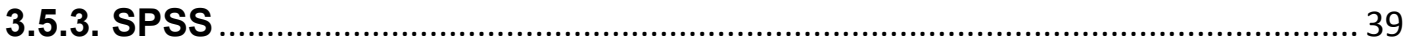

3.6. Procedimiento y Recolección de Datos ............................................................... 39 


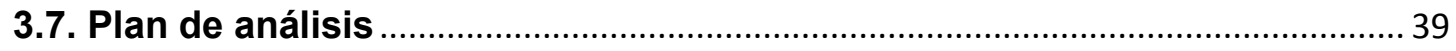

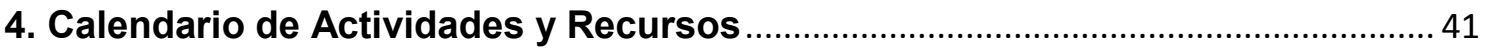

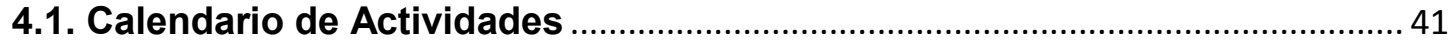

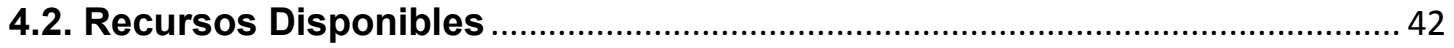

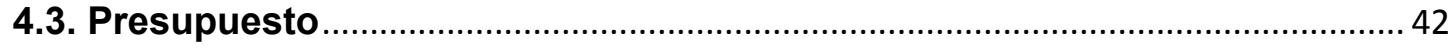

5. Resultados

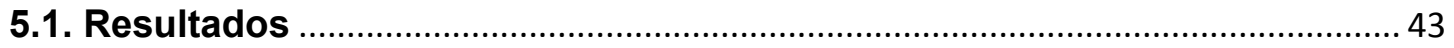

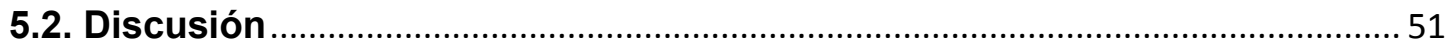

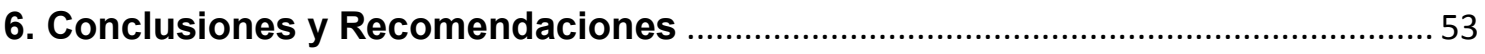

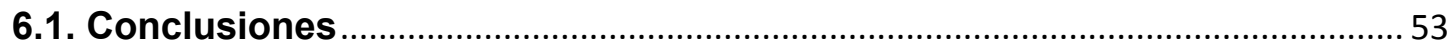

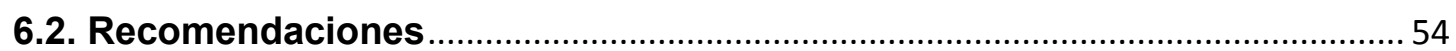

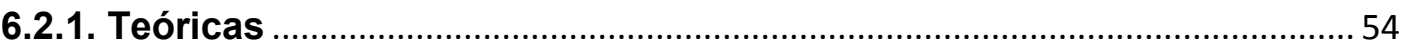

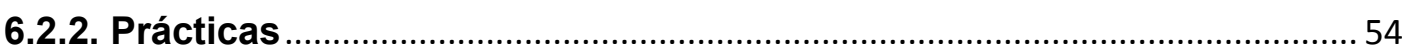

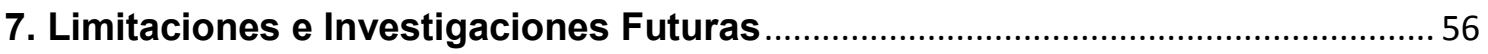

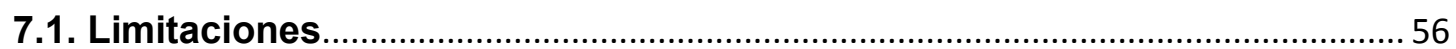

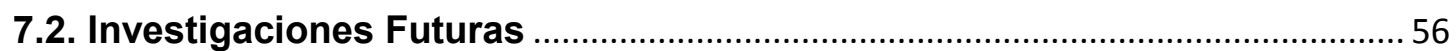

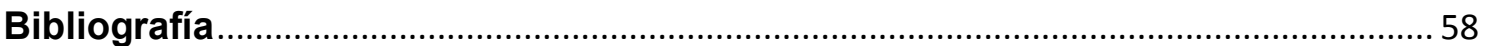




\section{Índice de Tablas}

Tabla 1: Modelo Big Five y sus componentes ...................................................... 19

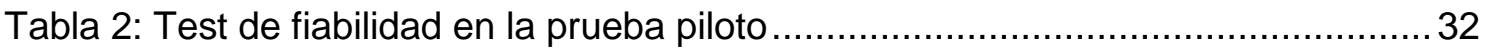

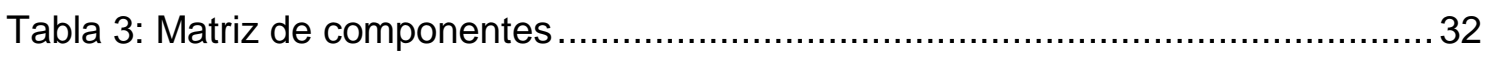

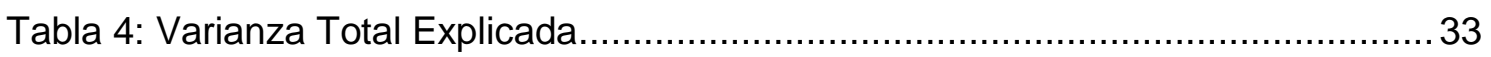

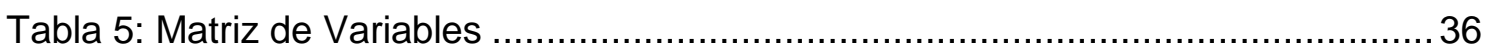

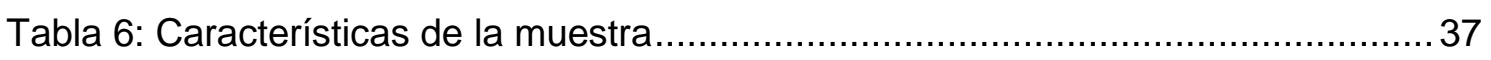

Tabla 7: Cuestionario Big Five Extra Short (Extra corta) .......................................... 38

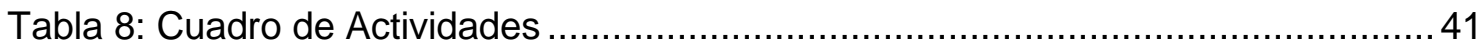

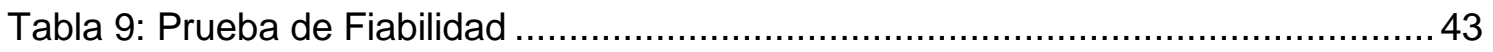

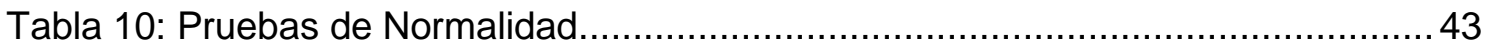

Tabla 11: Matriz de correlaciones entre preferencias musicales y componentes del Big

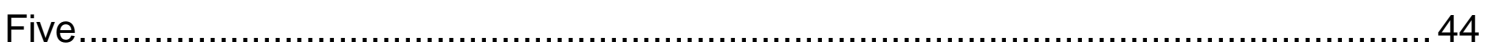

Tabla 12: Prueba U de Mann-Whitney- Genero del participante vs. Modelo Big Five.. 46

Tabla 13: Correlación de la edad con las preferencias musicales .............................. 46

Tabla 14: Correlación entre el rango de edad y el Modelo Big Five .............................51 


\section{Índice de Figuras}

Figura 1: Frecuencia con la que la que las personas declaran escuchar música Región Lima

Figura 2: Género musical preferido por peruanos (Respuesta Única) ........................ 11

Figura 3: Gráfico de sedimentación para componentes ............................................ 33

Figura 4: Media de los componentes del Big Five de acuerdo al género del participante

Figura 5: Nivel de preferencias por la cumbia de acuerdo al rango de edad .47

Figura 6: Nivel de preferencias por el Festejo de acuerdo al rango de edad 47

Figura 7: Nivel de preferencias por el Festejo de acuerdo al rango de edad 48

Figura 8: Nivel de preferencias por el Festejo de acuerdo al rango de edad 48

Figura 9: Nivel de preferencias por el Festejo de acuerdo al rango de edad..... 49

Figura 10: Nivel de Apertura de acuerdo al Rango de Edad 49

Figura 11: Nivel de Extroversión de acuerdo al Rango de Edad ................................50

Figura 12: Nivel de Simpatía de acuerdo al Rango de Edad .50

Figura 13: Versión de los resultados de Herrera, Soares-Quadros, \& Lorenzo (2018) para el caso de ciudadanos de Brasil

Figura 14: Versión de los resultados de Brown (2012) para el caso de estudiantes japoneses.

Figura 15: Versión computarizada el Modelo Big Five de personalidad aplicada a la cuenta en Twitter del Papa Francisco

\section{Índice de Anexos}

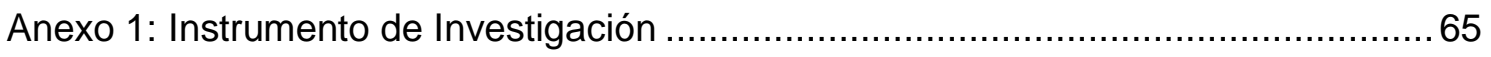

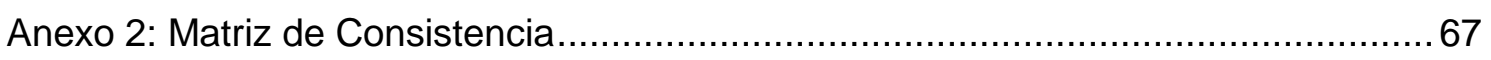

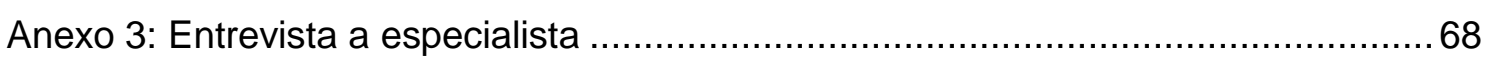

Anexo 4: Presentación de resultados publicado en revista internacional donde se usa Rho de Spearman para los componentes de personalidad y preferencias musicales .72 Anexo 5: Presentación de resultados publicado en revista internacional donde se usa análisis descriptivo y correlacional para las preferencias musicales y el genero .73 Anexo 6: Presentación de resultados publicado en revista internacional donde se usa análisis correlacional entre el rango de edad y las preferencias musicales. 74

Anexo 7: Resultados de Watson Personality Insights para una data de prueba. 75 


\section{Problema de Investigación}

\subsection{Planteamiento del Problema}

Los consumidores poseen insights en sus personalidades, estos se ven reflejados de alguna manera en los productos que deciden consumir (IBM, 2016). Los consumidores adquieren productos desde automóviles hasta agua embotellada para destacar u ocultar algún aspecto del Yo (Quiñones, 2008). Algunos productos son seleccionados en función a la coherencia con el Yo real y otros porque permiten a los consumidores estar cerca de su Yo ideal (Solomon, 2008). Las preferencias musicales también están vinculadas a la personalidad (Nave \& Kosinski, 2018).

La música parece ser un elemento importante en la mayoría de las sociedades. En el Perú, la música es escuchada en casi todas partes; desde tiendas de abarrotes hasta eventos deportivos. Además, la gente opta por escuchar música por su cuenta comprando álbumes, compartiendo música en línea y descargando canciones. Los estudios han demostrado que cada individuo tiene su propio gusto único para música y preferencia por ciertos géneros musicales. Sin embargo, el estudio de las preferencias musicales es relativamente nuevo; todavía quedan varias preguntas sin responder.

A tal punto ha llegado la importancia de modelar la personalidad que diversas empresas han procurado automatizar el proceso. Tradicionalmente, los tests psicológicos que permiten conocer la personalidad del individuo son particularmente extensas (IBM, 2016). Multinacionales como IBM han optado por un camino distinto: la psicolingüística aplicada a datos en formato de texto libre en una red social. Dado que esta tecnología es de muy reciente incorporación, es natural que el número de investigaciones relacionadas a este tópico sean todavía muy escasas.

IBM, a través de su software Watson Personality Insights, una inteligencia artificial propiamente dicha (Deloitte, 2015) ha logrado modelar la personalidad de la persona en base a lo que comenta en redes sociales como Twitter. Este instrumento cuenta con una versión online gratuita que puede ser aprovechada por otros investigadores interesados en el estudio de los insights de la personalidad, principalmente psicólogos y profesionales del marketing. No requiere de conocimientos de programación, pero sí de una adecuada comprensión en cuanto a los resultados. De acuerdo a la multinacional, Watson Personality Insights fue desarrollado correlacionando resultados de un test de personalidad con el algoritmo desarrollado para Watson. 
Si se trata de personalidad con evidencia en actividad web, J. Golbeck., C. Robles., M. Edmodson. \& K. Turner. 2011, orientaron su investigación a la predicción de la personalidad en base a comentarios en Twitter. Para ello, analizaron a 279 individuos con cuentas en la mencionada red social. Fueron analizadas las 2,000 últimas publicaciones de cada usuario con el instrumento ZeroR. El resultado del análisis fue comparado con los indicadores obtenidos a partir del test de personalidad escrito que cada participante completó. Los investigadores demostraron que existía correlación entre los resultados, concluyeron que Twitter podía ser empleado para predecir la personalidad de las personas.

¿Qué tenían en común las investigaciones de J. Golbeck. 2011 e IBM (2016)? Ambos utilizaron métodos de analísis lingúistico computacional y tests psicológicos. Pero tanto la versión computacional como el instrumento aplicado empleaban como base un único soporte teórico: el modelo Big Five de personalidad. El hecho de que haya sido adaptado para un análisis psicolinguistico realizado por computadora evidencia la enorme versatilidad del modelo.

Han existido múltiples modelos que han procurado dimensionar la personalidad (Goldberg, 1992). El modelo Big Five construido con los aportes de P. Costa. \& R. McCrae. 1992, y W. Norman. 1963, ha sido uno de los de mayor impacto académico. Las aplicaciones han sido múltiples. Tal como señala IBM (2016), el modelo ha sido empleado para comprender diversos aspectos del comportamiento humano. Así, ha sido aplicado para comprender el comportamiento criminal, el rendimiento académico, las tendencias políticas, patrones de consumo, preferencias musicales, etc.

Distintas investigaciones han procurado relacionar a los elementos asociados a la personalidad y las preferencias musicales. Estas han buscado romper estereotipos. Así, por ejemplo: la violencia que rodea al heavy metal no forma parte de la personalidad de sus seguidores ya que su gran mayoría, son personas amables y pacíficas. Ejemplos como en anterior, muestran cómo existen elementos de la personalidad que pueden estar asociados (o no) a las preferencias musicales.

En el Perú apenas existen investigaciones relacionadas a las preferencias musicales. La consultora GFK (2017) realizó uno de las escasas investigaciones vinculadas a la música, que escuchaban y bailaban los peruanos. Con respecto a la región Lima, fueron obtenidos los siguientes resultados: 


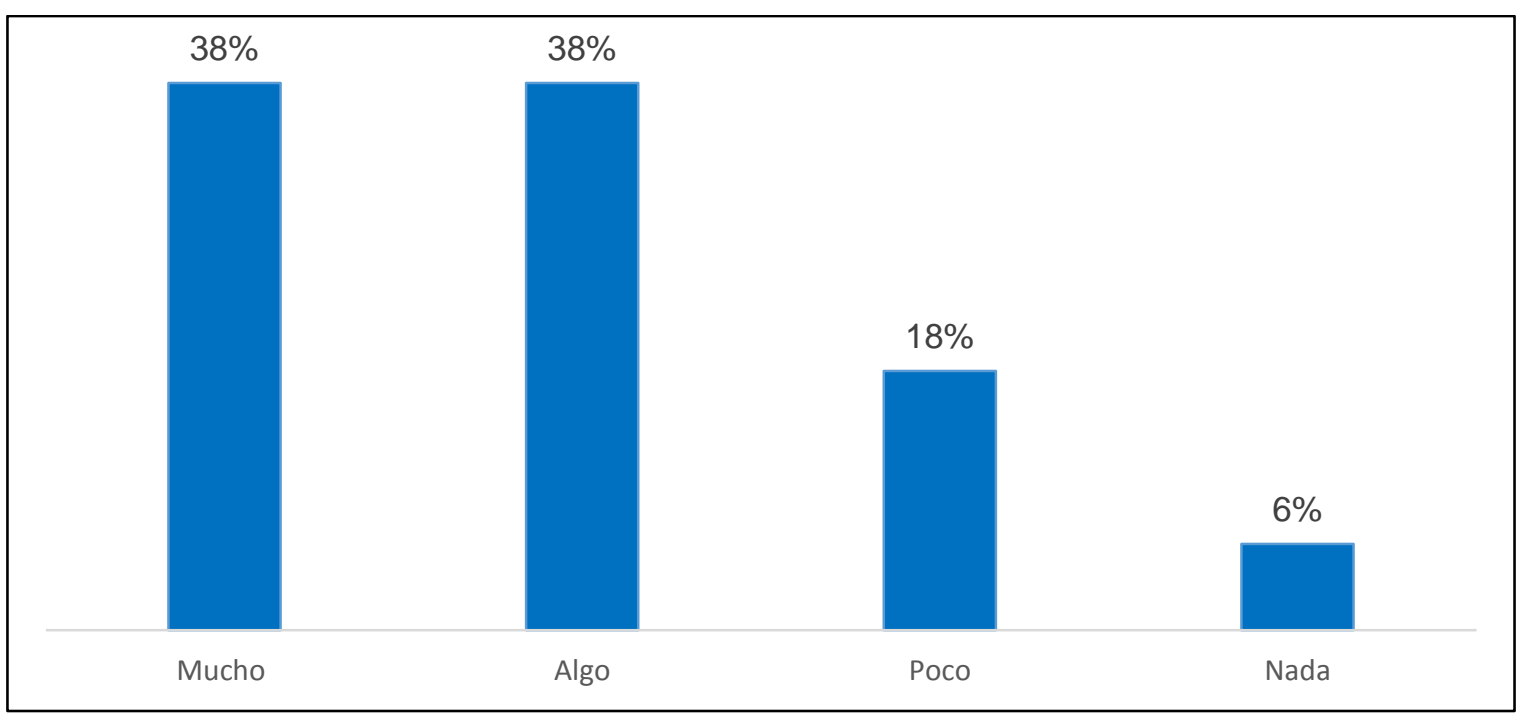

Figura 1: Frecuencia con la que la que las personas declaran escuchar música Región Lima

Fuente: GFK (2017)

De acuerdo a GFK (2017), en Lima se escucha música con más frecuencia que en el interior del país. Los géneros más escuchados son los siguientes:

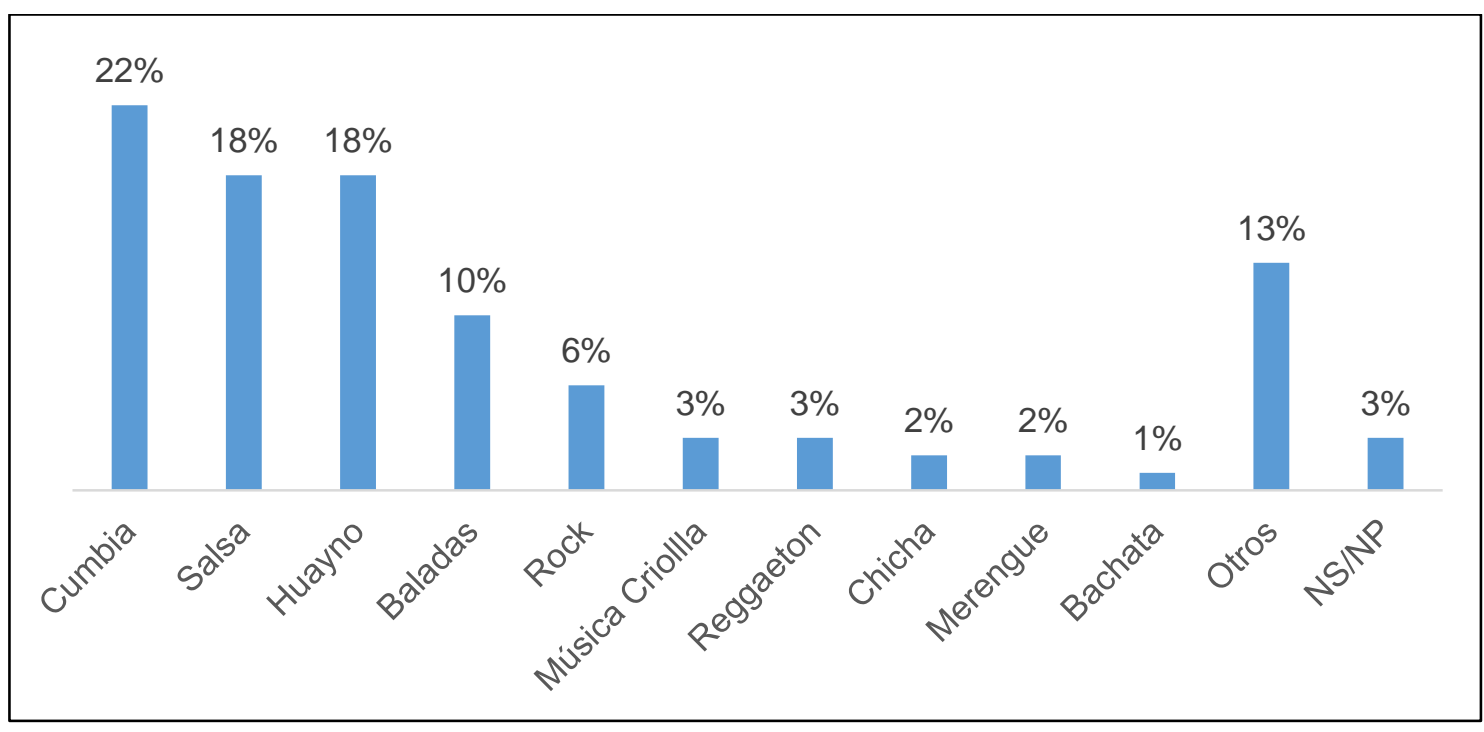

Figura 2: Género musical preferido por peruanos (Respuesta Única)

Fuente: GFK (2017)

Nota: En la categoría otros está incluído los siguientes géneros: clásica, pop en español e inglés, disco, hip hop, electrónica, rock progresivo, reggae, festejo, metal, saya, trova, jazz y blues. 
Dada la trascendencia del modelo Big Five y sus componentes y la poca atención que han recibido las preferencias musicales como campo de estudio; el presente documento está orientado a conocer una posible relación entre los componentes del Modelo Big Five de Personalidad y las preferencias musicales en el caso de adultos residentes en Lima.

\subsection{Formulación del Problema}

¿Existe relación entre los componentes del Modelo Big Five de Personalidad y las preferencias musicales en adultos que residen en Lima?

\subsection{Justificación}

En cuanto al marketing, la investigación se centra en descubrir los insights de la personalidad, componentes fundamentales para comprender por qué un consumidor prefiere tal o cual producto (Solomon, 2008). En este caso aplicado a los géneros musicales.

Por otro lado, en cuanto al marketing electrónico, se ha demostrado que quienes poseen un alto grado de Apertura y un bajo nivel de Neurocitismo (ambos, rangos de la personalidad bajo el modelo Big Five) son más propensos a hacer clic en un anuncio o seguir a una cuenta; mientras que aquellos que son más extrovertidos, tienden a responder más o compartir un contenido (Fast \& Funder, 2008). De esta forma, es posible sacar datos que son de provecho para la industria musical, en especial en un entorno dominado por los medios digitales.

El cuestionario del modelo Big Five original consistía de 132 preguntas en escala de Likert. Es probable que, debido a su extensión, muchas personas lo encuentren incómodo. Además, múltiples aportes han evidenciado que el cuestionario puede ser acortado sin necesidad de sacrificar su calidad. Así, el cuestionario ha pasado a contar con una versión de 60 preguntas. Las dos versiones más recientes constan de 30 preguntas (versión corta) y 15 preguntas (versión extra corta). A fin de procurar una mayor tasa de respuestas, los investigadores han creído conveniente aplicar la versión de 15 preguntas. Cabe mencionar que, dicho instrumento no ha sido empleado en investigaciones de habla hispana.

En el ámbito académico peruano, algunas investigaciones han empleado el modelo Big Five. Sin embargo, no se han ubicado investigaciones que correlacionen a 
dicha simplificación de la personalidad con las preferencias musicales. Por tanto, la investigación pretende indagar un campo inédito en la producción académica peruana. $Y$ ello es importante porque una investigación debe procurar la originalidad a fin de aportar al conocimiento científico. 


\section{Marco Teórico}

\subsection{Antecedentes}

P. Rentfrow. \& S. Gosling. 2003, derivaron los siguientes cuatro géneros de preferencia musical vía análisis factorial de su Prueba Corta de Preferencias Musicales (STOMP): complejo reflexivo (RC; blues, jazz, clásico y folk); intenso-rebelde (IR, rock, alternativa y heavy metal); optimista-convencional (UC, country, banda sonora, religiosa y pop); y enérgico-rítmico (ER; rap /hip-hop, soul / funk y electrónica / dance). Se han observado correlaciones positivas significativas entre la Apertura a la experiencia y las preferencias por los géneros de música $R C$ e $I R$, con apertura a la experiencia inversamente ligado a la preferencia de música UC, mientras que la Extraversión ha sido positivamente vinculada a la preferencia de música ER. Los investigadores realizaron su investigación con estudiantes de pregrado en Alemania, reprodujo las asociaciones antes mencionadas entre la apertura a la experiencia y las preferencias de RC, IR y Géneros musicales de UC, además del vínculo entre extraversión y preferencia de ER, extendiendo sus hallazgos para sugerir relaciones adicionales entre la extraversión y el aumento de preferencia por la música IR, y el Neuroticismo siendo positivamente predictivo de las preferencias y predictivo de la preferencia de IR.

R. Brown. 2012, señaló que en la literatura académica los estudios que vinculan rasgos de la personalidad y preferencias musicales se había centrado solo en contextos estadounidense y europeo. Por ello, el investigador decidió estudiar el segmento de japoneses, específicamente a estudiantes universitarios. La investigación pretende establecer correlaciones entre 12 géneros musicales y 24 rasgos de la personalidad. Los resultados fueron consistentes con los antecedentes académicos. Así, la apertura hacia nuevas experiencias y más específicamente la apreciación hacia lo estético tenía relación con la música reflectiva (dimensión que fue construida a partir del instrumento STOMP en donde se incorporaba el jazz, clásica, ópera, góspel y enka). Por otro lado, el nivel de preferencia por el pop tiene relación con la Extroversión. Las otras correlaciones entre preferencias musicales y rasgos de la personalidad no fueron particularmente fuertes.

D. Tully. 2012, examinó el efecto de la edad en la relación entre preferencia musical y tipo de personalidad. Este estudio se realizó a 109 participantes que viven en Irlanda. El investigador empleó la Prueba Corta de Preferencias Musicales 
(STOMP), diseñada por P. Rentfrow. y S. Gosling. 2003, para evaluar los tipos de música preferidos por los participantes, y el Inventario de personalidad Big Five. El investigador examinó las estructuras de personalidad de los individuos, la muestra estaba formada por conveniencia: eran estudiantes de psicología que asisten a Dublin Business School, y otros participantes que completaron la encuesta en línea. Los resultados del estudio indicaron que existe una correlación entre algunos factores de preferencia de la música (reflexivo / complejo, intenso / rebelde, energético y rítmica) y algunos rasgos de personalidad (Apertura, Extroversión). Los efectos de la edad no fueron concluyentes.

S. Miranda. 2013, tuvo entre sus objetivos describir los rasgos de la personalidad de estudiantes argentinos de entre 14 y 18 años. En una segunda etapa buscó determinar si dichos rasgos tenían relación con determinadas preferencias en cuanto a escuchar música. La muestra incluyó a 238 participantes, quienes eran estudiantes de cuatro escuelas argentinas. Entre los resultados, cabe mencionar que, quienes escuchaban música romántica eran sujetos con un mayor de apertura y sensibilidad. En la etapa descriptiva propiamente dicha, el investigador evidenció que la Extroversión es el rasgo que más resaltaba entre los participantes, específicamente se destacó la calidez de las emociones y la amabilidad de los estudiantes.

E. Vella. \& G. Mills. 2017, tuvieron como objetivo determinar si los usos de la música median parcialmente el vínculo entre personalidad y preferencia musical. Los estudiantes de pregrado ( $N=122$ ) completaron las siguientes escalas: El inventario de personalidad Big Five, Inventario de Usos de la Música, The Short Test of Music Preference (STOMP), La Prueba de Orientación de Vida Revisada, Inventario de Depresión de Beck y La Escala de Estrés Percibido. Entre los resultados obtenidos, se evidenció que la Apertura se relaciona con el complejo refelxivo $(\mathrm{RC}$, por ejemplo, jazz / blues) y música intensa-rebelde (IR, por ejemplo, rock / metal) ya estaba inversamente relacionada con optimista-convencional (UC, por ejemplo, country / pop), mientras que la Extroversión se relacionó positivamente con las preferencias por enérgico-rítmico (ER, por ejemplo, rap / soul) y géneros. La preferencia estuvo completamente mediada por el rasgo de Extroversión más prominente. La relación entre la Apertura a la experiencia y la preferencia de la música $R C$ estuvo parcialmente mediada por los usos cognitivos de la música, con un análisis marginalmente significativo que indica una mediación parcial de los usos emocionales de la música para apertura a la experiencia y preferencia de música IR. Los hallazgos 
apoyan el estudio de personalidad contextualmente junto con los usos de la música cuando se investigan las preferencias musicales y arrojan luz sobre cómo el afecto negativo puede informar los usos emocionales de la música.

L. Herrera. Q. Soares-Quadros. \& O. Lorenzo. 2018, tuvieron por objetivo analizar la relación entre la preferencia musical y el tipo de personalidad en un gran grupo de participantes jóvenes y adultos brasileños $(N=1050)$. El estudio incluyó 25 de los 27 estados de Brasil y personas de edades comprendidas entre 16 y 71 años $(\mathrm{M}=30.87$; $\mathrm{SD}=10.50)$. De estos, 500 eran hombres (47.6\%) y 550 mujeres $(52.4 \%)$. Los investigadores llevaron a cabo un estudio correlacional aplicando dos cuestionarios en línea con parámetros de calidad (validez y confiabilidad del contenido del constructo), uno sobre preferencia musical y otro sobre personalidad. Los resultados indicaron cuatro hallazgos principales: (1) La escucha musical de los participantes se limita a un número reducido de estilos, principalmente música pop y otros, típicos de la cultura brasileña; (2) El contexto brasileño supone un aspecto determinante en la baja preferencia de la música no brasileña; (3) Existe una correlación positiva entre la mayoría de los tipos de personalidad analizados y los estilos musicales latino, brasileño, clásico y étnico. También, se observó una correlación negativa entre estos tipos de personalidad y el consumo de música rock; (4) Las preferencias musicales están impulsadas no solo por la personalidad, sino que, en algunos casos, también están impulsadas por variables sociodemográficas (es decir, edad y género). Asimismo, este trabajo muestra cómo los participantes utilizan la música en aspectos de la personalidad que pueden ser de interés para el análisis del comportamiento socioafectivo (personalidad), así como de acuerdo con diferentes variables sociodemográficas (por ejemplo, edad y género). Más investigación intercultural sobre la preferencia musical y la personalidad tendría que llevarse a cabo desde una perspectiva global, enmarcada en el contexto de la psicología social y los estudios de comunicación masiva. 


\subsection{Marco Teórico}

\subsubsection{Música}

La música representa un concepto muy amplio, por ello, es necesario citar una diversidad de autores para definirla. Según la definición del Diccionario de la Real Academia de Lengua Española -editado por la Real Academia Española-, la música es el arte de combinar los sonidos de la voz humana, de instrumentos o de ambos juntos, a fin de producir deleite, conmoviendo sensibilidades para alegría o tristeza. Por otro lado, V. Lemos. 1997, indica que, a través del ritmo, la melodía, la armonía, y, en sí, el sonido de la música, es posible que el ser humano se vea beneficiado, ya que eleva el nivel cultural, reconfortando y trayendo alegría tanto al compositor como al ejecutante y, por último, al oyente. Estando siempre ligada al progreso de la historia humana, la música ha adoptado diversas formas y significados a través de las épocas.

G. Mottini. 1944, argumenta que el murmurar de las aguas y del viento, las voces de los hombres y el sonido de los pájaros ya son música. L. Rowell. 1985, por otro lado, indica que la música, al menos en potencia, es un arte social, que siempre ha estado cerca del hombre, incluso en las edades primitivas.

J. López. (s.f.) evidencia que es posible distinguir, desde el principio de la historia humana, el poder que los sonidos poseen sobre el comportamiento de los seres vivos. La música consta con un efecto influenciador en el plano emocional además de comportar resonancias afectivas profundas. J. Pahissa. 1954, indica la naturaleza verdadera de la música como: abstracta y espiritual, y es por eso que nos produce una impresión de tan alta y pura belleza.

\subsubsection{Definiciones de Personalidad}

J. Piaget. 1991, señaló que la personalidad es el resultado de la auto sumisión del yo bajo una disciplina cualquiera, por ende, necesariamente la personalidad es una asistencia del individuo. Luego, G. Sepúlveda. 2001, nos comenta que la personalidad vendría a ser una metamorfosis en que el niño se descentra del yo, enfocandolo en un esquema de colaboración y subordinándolo a disciplinas autónomas. En discrepancia, S. Maddi. 1972, indica que personalidad sería un conjunto de inclinaciones y características que 
permanecen continuamente, determinando semejanzas y diferencias entre las personas debido a sus conductas psicológicas, denotando persistencia en el tiempo y pudiendo interpretarse según las normas sociales y biológicas de presión que se originan en una situación inminente. Estas tendencias son aquellas que determinarán pensamientos, sentimientos y actos de la persona, los que parecen direccionales o al servicio de objetivos y funciones. Luego, J. Nuttin. 1973, precisa que la personalidad no es más que una producción del psicólogo, para idear o inventar una idea (a nivel de hipótesis científica) del cómo es y actúa característicamente el organismo psicofisiológico que se da en aclamar persona humana. Por otro lado, J. Cohen. 1980, señaló que la personalidad también es explicada como la recopilación abstracta de ciertas predisposiciones al confesar a los estímulos de un modo específico o determinado, sean estas instruidas o innatas, pero, imposible de observar directamente, de esta forma es que la personalidad se decreta la conducta distintiva de cada alma. Luego, Lafuerza (s.f.) nos señala que la personalidad es la expresión del patrón de individuo que se es, ya que comprende las características y cualidades que impulsan a la persona a la acción y su conducta, reiterando el diseño del que es la que discrepancia entre personas y puede llegar a revelar tendencias y peculiaridades.

S. Maddi. 1972, precisa que se determina dos tipos de proposiciones en relación a la personalidad, la primera de ellas traza aspectos más usuales a las personas, las que evidencian características inherentes de los individuos, estos, no alteran mucho a lo largo de la existencia, sin embargo, ejercen una gran autoridad sobre la conducta, éste sería el foco de la personalidad. La otra clase de proposiciones propone formulaciones sobre atributos mucho más certeros y próximos a la conducta perceptible, estas proposiciones se utilizan para manifestar desemejanzas entre las personas. Debido a que son elementos aprendidos, estos atributos vendrían a ser la periferia de la personalidad. 


\subsubsection{Modelo Big Five}

El modelo de personalidad Big Five (o Cinco Grandes) es uno de los modelos de personalidad mejor estudiados, desarrollado por los psicólogos P. Costa. \& R. McCrae. 1992, y W. Norman. 1963. Es el modelo de personalidad más utilizado para describir cómo una persona generalmente se interrelaciona con el mundo. P. Costa. \& R. McCrae. 1992, definían como un compuesto de tendencias básicas de la conducta, la que influirá en los pensamientos, emoción y el accionar de un individuo. Es de principio biológico y su progreso inicia en la niñez, prosigue incluso transformarse en una organización firme en la época adulta, organizándose de carácter jerárquica.

Tabla 1: Modelo Big Five y sus componentes

\begin{tabular}{|c|c|c|}
\hline Modelo & Dimensiones & Personas con un alto puntaje \\
\hline \multirow{15}{*}{ Big Five } & \multirow{3}{*}{$\begin{array}{l}\text { Apertura: describe la amplitud, profundidad, originalidad y complejidad de } \\
\text { la vida mental y aquella derivada de la experiencia de una persona. }\end{array}$} & Están fascinadas con el arte música o literatura. \\
\hline & & $\begin{array}{l}\text { No les llama la atención las ideas concretar y lógicas, pueden } \\
\text { preferir cuestiones abstractas. }\end{array}$ \\
\hline & & Son originales y proponen nuevas ideas. \\
\hline & \multirow{3}{*}{$\begin{array}{l}\text { Neuroticismo: contrasta la estabilidad emocional y un ánimo estable con } \\
\text { la emocionalidad negativa, tal como sentirse ansioso, nervioso, triste y } \\
\text { tenso. }\end{array}$} & Tienden a preocuparse en exceso por las cosas. \\
\hline & & Son propensos a deprimirse o ponerse tristes. \\
\hline & & No son emocionalmente estables y se alteran fácilmente. \\
\hline & \multirow{3}{*}{$\begin{array}{l}\text { Responsabilidad: describe el control de los impulsos que es prescrito } \\
\text { socialmente y facilita los comportamientos dirigidos al logro de tareas y } \\
\text { metas, como pensar antes de actuar, postergar las recompensas, seguir } \\
\text { normas y reglas, y planear, organizar y priorizar las tareas. }\end{array}$} & Presentan tendencia a ser organizados. \\
\hline & & No tienen dificultad para iniciar tareas. \\
\hline & & Son percibidos como personas confiables por sus pares. \\
\hline & \multirow{3}{*}{$\begin{array}{l}\text { Extroversión: implica una aproximación energética hacia el mundo social } \\
\text { y material e incluye rasgos como sociabilidad, actividad, asertividad y } \\
\text { emocionalidad positiva. }\end{array}$} & Son muy efusivos, no son callados. \\
\hline & & Actúan como líderes y pueden llegar a ser dominantes. \\
\hline & & Son percibidos como personas llenas de energía. \\
\hline & \multirow{3}{*}{$\begin{array}{l}\text { Simpatía: contrasta una orientación pro social y comunal hacia los otros } \\
\text { con el antagonismo, e incluye rasgos como altruismo, ternura, confianza y } \\
\text { modestia. }\end{array}$} & $\begin{array}{l}\text { Tienden a preocuparse por los demás, llegan a tener lo que se } \\
\text { denomina un buen corazón. }\end{array}$ \\
\hline & & Son muy corteses en su trato hacia los demás. \\
\hline & & Presentan una tendencia clara a pensar lo mejor de las personas \\
\hline
\end{tabular}

Fuente: Basado en las definiciones de P. Costa. \& R. McCrae. (1992), W. Norman. (1963) y C. Soto. \& P. John. (2017). 


\subsubsection{Preferencias Musicales}

Los considerables avances en la investigación de las preferencias musicales en los últimos años han seguido poniendo de relieve la complejidad de este tema. Las preferencias musicales están influenciadas por una multitud de factores que van desde lo amplio (por ejemplo, los contextos culturales y sociales) hasta lo específico (por ejemplo, la edad, la preferencia por las características musicales, los usos de la música), y determinar la influencia relativa de éstas en las preferencias representa un desafío permanente para el campo. Si bien el nivel de generalización y reducción empleado en los estudios sobre las dimensiones de las preferencias pone de relieve algunos vínculos bastante coherentes entre las preferencias y otras variables (como edad, sexo y la personalidad), las personas interpretan los diferentes estilos de diferentes maneras y la proliferación cada vez mayor de categorías de estilos, A.Greasley., A. Lamont. \& J. Sloboda. 2013.

Lo anterior significa que cuanto mayor sea la reducción, menor será la probabilidad de que los estudios reflejen las preferencias reales de las personas de una manera significativa, A. Greasley. 2008. Los estudios que exploran cómo la predilección por características específicas de la música influye en la preferencia han puesto de relieve que ésta varía tanto entre los individuos como dentro de ellos, lo que limita las conclusiones que pueden extraerse. De acuerdo a M. Maffesoli. 1996, existe una distinción entre centrarse en estilos y características generales y en piezas específicas que a menudo no son suficientemente reconocidas; los investigadores deben considerar el tipo de preferencia (por ejemplo, estilo, artista, tema, características musicales).

La obra de A. Bonneville-Roussy. 2014, es la más cercana a la fecha, que encuentra un compromiso entre un enfoque en los estilos musicales y un enfoque en las características musicales. Un área que no ha recibido suficiente atención se refiere a la naturaleza efímera de las preferencias musicales. La gente informa de que sus preferencias están cambiando todo el tiempo, tanto en el día a día como a lo largo del tiempo y esto tiene implicaciones para cualquier enfoque que asuma que la respuesta de un individuo a la música en un momento dado es representativa de sus preferencias musicales de manera más general. Sí, como sugieren A. Greasley. 2013, y A. Langemeyer. 2012, una teoría de las preferencias musicales debería explicar la trayectoria de las 
preferencias en el tiempo, entonces el trabajo futuro debe emplear diseños longitudinales. Los estudios podrían trazar un mapa del compromiso con diferentes estilos y artistas durante períodos de tiempo específicos, aunque se reconocen las dificultades de controlar y/o registrar con precisión la exposición de las personas a la música en la vida diaria (Gaytán, 2001). La investigación cualitativa que adopta un enfoque del ciclo vital (como el que ofrecen las entrevistas narrativas) es probable que proporcione una visión de la dimensión temporal de la preferencia musical, proporcionando un equilibrio necesario a la riqueza de la investigación experimental y psicométrica en este campo (Greasley, 2008).

J. Ramírez, precisa que las preferencias musicales no han sido estudiadas a fondo como anómalo académico. Menciona que un fragmento de los motivos de esta apatía obedece a que, en realidad, se trata de un fenómeno correspondientemente actual, que probablemente se inicia en la segunda mitad de siglo $\mathrm{XX}$. De inicio, las colectividades que se han resignado en torno a algunos géneros musicales han sido vistas desde perspectivas que contienen prejuicios excesivos y que las catalogan sencillamente como "masas", sobre todo juveniles, que son manipuladas por las industrias culturales a través de la moda, que siempre tiende a lo artificioso y que origina, perseverantemente, un mercado de consumo masivo.

J. Ramírez. 2006, además indicó que una corriente influyente en este sentido es la de la Escuela de Frankfurt, en la que se predomina los planteamientos del filósofo alemán Theodor Adorno. Algo verídico en esta tendencia, pero se tiende a una generalización exagerada que no permite observar algunas cualidades y condiciones de lo que es propio de una persona, importantes de estas colectividades. Por otro lado, aquellos que han encarado el fenómeno de modo distinto, han tendido a tomar posesión de criterios de interpretación diferentes al que se plantea, como, por ejemplo, los llamados "teóricos de la posmodernidad". Un caso es del filósofo francés Michel Maffesoli que considera que, en realidad, sucede un desplazamiento en las formas de sociabilidad que tienden a formar un declive del individualismo en favor de lo colectivo que se concreta en "tribus". Esta es una generalización excesiva en medida que no se analiza las especificidades de cada tribu, pues si eso se ejecutará se llegaría a un desenlace que la categoría no designa lo que se pretende, salvo en algunos contextos. Además, la conducta de las diferentes identidades socio-musicales no obedece al sentido de la corriente histórica 
"descubierta" por M. Maffesoli. 1996, todos los principios que sustentan esta corriente que, según él, nos sitúan en un campo "posmoderno", son completamente discutibles.

En otra perspectiva, se han realizado otras investigaciones que han privilegiado el estudio de estas colectividades apoyándose en aspectos biológicos, culturales, sociales e históricos que fijan con claridad a sus participantes como "jóvenes" (Gaytán, 2001). A partir de la problematización de esta clase se enfatiza la transcendencia de la "música juvenil" en la edificación de las llamadas "identidades juveniles". Estas investigaciones han estado muy vinculados al análisis urbano, que da seguimiento a los actores sociales de la ciudad en sus prácticas y sus espacios (Ramírez, 2006). En América Latina se realizado varios estudios al respecto (Ramírez, 2006). La literatura es cuantiosa. Estudios referente las políticas culturales juveniles, reconstrucciones etnográficas de espacios sociales, teorización acerca del entorno de las colectividades, definiciones de procesos de construcción identitarios, estudios sobre las relaciones de género dentro de los diversos grupos sociales juveniles, trabajos sobre consumos culturales, seguimientos de los procesos de territorialización o desterritorialización, investigaciones hermenéuticas de lo que se ha dado en llamar culturas urbanas, etc (Gaytán, 2001). En la totalidad de esta literatura se privilegia la categoría de "juventud urbana", de tal modo que ésta termina siendo un supuesto de investigación casi incuestionable (Gaytán, 2001).

J. Ramírez. 2006, preciso que, llama la atención que en las investigaciones de diversos actores sociales agrupados en torno a música la categoría "juventud" o "juventud urbana" resulta irrelevante, casi al grado de inexistente. Ello, disminuye importancia a estas investigaciones, al contrario, provoca a plantear una clase nueva que brinda situaciones de indicar el cimiento de alguna de estas colectividades, lo cual implica señalar que la preferencia musical es base de algunas identidades sociales, de aquellas que ha llamado identidades socio-musicales (Gaytán, 2001).

El siglo XX ha proporcionado nuevas formas de abordar el estudio de las identidades. La naturaleza de éstas, a través de la interpelación discursiva, propicia que se privilege el espacio de lo social como el ámbito calificado para cumplirlas. Las identidades sociales, a partir de la segunda mitad de siglo XX, han enfrentado un nuevo espacio en su proceso de producción dentro del 
campo de lo social: la música (Ramírez, 2006). La semejanza académica entre música y sociedad ha desplegado a reflexionar la parte musical como accesoria a una identidad. La música es expresión de una identidad social y bajo esta perspectiva se ha realizado una gran cantidad de trabajos (Gregory, 1997). Esta es una correlación viable entre música y sociedad (Gaytán, 2001). De hecho, que la música goza para algunas identidades sociales un carácter accesorio, ha sido una acción histórica y continúa siéndolo (Ramírez, 2006). Además, se ha estimado que las audiencias musicales masivas son fruto de una manipulación ideológica de las industrias culturales con el único ánimo de comerciar sus productos (Gaytán, 2001). Este horizonte no es del todo falsa, pero su parte fructífera ha quedado oscurecida por los prejuicios que han creado en torno a la semejanza entre la música popular de la segunda mitad del siglo XX y sus audiencias (Ramírez, 2006).

La música se ha manifestado como un mecanismo de generación de identidades que no se ha sido investigada de modo específica y exuberante, sino solo en sus contornos, donde el rock posee un lugar predilecto como objeto de estudio (Maffesoli, 1996). El estudio de las audiencias, vinculadas al sentido de la audición musical y al contexto histórico de la recepción, les permite comprender la expresión musical, en tanto discurso social, es un mecanismo que crea identidades (Ramírez, 2006). Dichas identidades han sido catalogadas como identidades socio-musicales, estas mismas poseen características específicas en su sentido de posesión, grado de compromiso, semejanza con la alteridad, exposición pública, memoria histórica, espacios sociales y prácticas colectivas que expresan una transparente definición identitaria (Maffesoli, 1996). Este razonamiento queda constituido sobre la preferencia musical (Ramírez, 2006). Si es accesible desplegar estudios e investigaciones de asuntos que nos pongan en contexto de comprender las especificidades y comportamientos de las identidades socio-musicales contemporáneas, tal como se han venido constituyendo a partir de un sentido socio-histórico-estético (Ramírez, 2006).

\subsubsection{Música y su relación con la personalidad}

E. Vella. \& G. Mills. 2017, indicaron que una creencia común es que la música afecta el estado de ánimo. Ciertamente las terapias musicales han sido empleadas en varios contextos para reducir la ansiedad e inducir a un estado de calma. Sin embargo, las variaciones en la música pueden inducir efectos 
diferenciales en el estado de ánimo. Por ejemplo, los directores a menudo seleccionan piezas musicales para "establecer un estado de ánimo" para una escena de película. La música es un componente esencial de muchas actividades sociales y las diferencias en las preferencias musicales tienden a variar ampliamente de persona a persona.

En coincidencia con el punto anterior, A. North. \& D. Hargreaves. 2009, mencionaron que factores pertinentes como la personalidad y su relación con las preferencias musicales han sido investigadas a fin de aproximarse a una predicción de la inducción musical en el estado de ánimo. La relación entre la personalidad y las preferencias artísticas han recibido una atención considerable de psicólogos a través de los años, en un esfuerzo por delinear aún más la utilidad predictiva de los rasgos en facciones específicas del comportamiento humano. Comprender las relaciones entre música que prefiere y la personalidad puede informar aplicaciones de terapias musicales.

K. Cleridou. \& A. Furhnham. 2014, mencionaron que de acuerdo a R. Cattell. \& D. Saunders. 1954, las primeras investigaciones sobre las asociaciones entre la preferencias musicales y la personalidad se centraron en la construcción de la Extroversión, observando asociaciones positivas significativas con preferencia hacia la música caracterizada por ritmos fuertes y rápidos. Recientemente, con el advenimiento del modelo de personalidad de cinco factores ampliamente respaldados, los hallazgos han señalado la importancia de la Apertura a la experiencia como un rasgo más robusto en la predicción de las preferencias estéticas.

Sin embargo, es importante tener en cuenta que la magnitud de la correlación entre Big Five rasgos de personalidad y las variables de preferencia de música tiende agruparse en un rango moderado (Langemeyer, 2012), lo que indica que hay otros factores en juego en predicción de preferencias musicales, como la forma en que los oyentes usan la música. T. Chamorro-Premuzic. y A. Furnham. 2007, desarrollaron un inventario para evaluar formas comunes en que las personas usan música en su vida diaria, obteniendo evidencia que indica que los oyentes usan la música como un medio de regulación de la emoción, estimulación cognitiva y como estímulo de fondo. De hecho, la evidencia sugiere asociaciones entre los usos de la música y las preferencias, según los cuales los usos cognitivos de la música predicen positivamente las preferencias de música IR y RC e inversamente predice preferencias por ER y música de UC. 
Además, T. Chamorro-Premuzic. y A. Furnham. 2007, formularon hipótesis y se encontraron pruebas de las diferencias individuales en los usos de la música, según las cuales los individuos con una alta calificación en Neuroticismo de rasgos, se encontró que usaba la música como un medio para regular la emoción. Mientras que, la Apertura a la experiencia se correlacionó positivamente con los usos cognitivos de la música. Estos hallazgos proporcionan un sentido de coherencia entre el rasgo y el comportamiento; individuos que experimentan un alto grado de afecto negativo como una función del Neuroticismo, este rasgo se puede predecir para participar en escuchar música como un medio para regular los estados de ánimo, al igual que aquellos fascinados por la estética, la belleza y el arte pueden usar la música como un medio de estimulación cognitiva al apreciar activamente la complejidad de las composiciones musicales. También, se ha formulado la hipótesis de que la Extroversión de rasgos correlaciona positivamente con los usos de fondo de la música (por ejemplo, escuchar música en el trabajo y durante eventos sociales como un medio para mantener un grado ambiental de estimulación auditiva).

Por consiguiente, el estado psíquico es apriorístico y a partir de este, cada individuo se deja conquistar por aquella música que encaja con su personalidad. En ocasiones, escuchar música con melodías o letras deprimentes no quiere decir que sea un factor detonante para deprimirse, sino que, al contrario, en ocasiones este tipo de música ayudan a superar bajos momentos de ánimo.

\subsubsection{Integración de Variables}

La gran mayoría de veces se relaciona el gusto musical con rasgos de personalidad, así como su estilo de pensamiento. S. Miranda. 2013, hace referencia al gusto musical como el conjunto de actitudes que el oyente tiene frente a una música determinada. Frente a ello, G. Stefani. 1987, define la música como un estilo de comportamientos, ya sea que sea usada como un estímulo para ciertas actividades, como es el caso de personas que usan cierto género de música para incitar a la relajación o; en otro caso, cuando el oyente la usa para estimularse.

La música ocupa un lugar muy importante en el ámbito cultural, en razón de que es una forma expresión desde los orígenes de la evolución. Si 
bien todas las culturas tienen instrumentos, cantan, bailan y estaban basadas en varios elementos comunes, cada cultura cuenta con una música propia que es materializada de manera distinta (Miranda, 2013). Por otro lado, en diversas culturas, la música es utilizada para estimular conscientemente comportamientos externos e internos, lo cual se puede reflejar en prácticas culturales de índole mágica, religiosa y terapéutica como comportamientos observados en salones de bailes o fiestas tradicionales (Greasley, 2008).

G. Stefani. 1987, señaló que los sonidos son ambiguos, por ejemplo, cuando una persona a falta de estímulos necesita concentrarse para trabajar, decide escuchar música instrumental, la cual le permite fluir con ella y llevar armonía a nivel personal. Ante este escenario, G. Stefani. 1987, y S. Miranda. 2013, indican que si bien existen sistemas, reglas y costumbres frente a los sonidos escenarios como este materializan la idea de que en esencia los sonidos son ambiguos; es decir, puede entenderse o interpretarse de diversas maneras.

Respecto a la percepción musical, D.Hargreaves. 1998, plantea que por lo general a las personas no les debería gustar la música percibida como muy simple o como muy compleja, con ello generando que se sientan atraídos con la música percibida como intermedia. Dado que estamos en un ámbito subjetivo, se plantea que para determinarla se tengan en cuenta dos puntos: complejidad objetiva de una pieza musical y la familiaridad del oyente respecto a la misma. Por ejemplo, una pieza musical sencilla tendrá distintas percepciones frente a un músico experimentado que a un no músico (Miranda, 2013). Por otro lado, existen percepciones que solo serán percibidas de manera particular, lo cual sucede con los estudiantes de música, cuando observan una imagen interna de la composición, la cual está conformada por: tiempo que lleva el ritmo, notas musicales, calidad del sonido y otros elementos no tangibles (Hargreaves, 1998).

Por otro lado, es imposible negar la serie de afectos que genera la música, ya que ésta puede originar imágenes y cadenas de pensamientos, los cuales se desarrollan a raíz de una mediación de aspectos conscientes y procesos inconscientes, lo cual finalmente se materialice en un afecto (Hargreaves, 1998). A raíz de estudios realizados por el conductismo, se aportó para el estudio de la psicología música resultados producidos por un determinado género musical. Resultados que indican que el tiempo que 
escucha un individuo una canción, será la media directa de su valor y significación que tiene para el individuo (Miranda, 2013).

Por los puntos mencionados anteriormente, existe una relación directa entre la estructura de la personalidad y la música que se decide oír, esta preferencia puede estar influenciada por distintos factores, ya sea por la edad, contexto social o interés y sobre todo los rasgos de personalidad (Miranda, 2013). De ahí, la afirmación que "somos lo que escuchamos".

\subsubsection{Marketing y Personalidad}

C. Graves. \& S. Matz. 2018, han señalado que los comunicadores y profesionales de marketing ahora pueden adoptar un enfoque personalizado para su trabajo, idealmente uno basado en la ciencia del comportamiento. Pero la ejecución está rezagada con respecto a la ciencia, mientras que las afirmaciones de algunos expertos en marketing sobre qué puede hacer el marketing de personalidad la superan. Además, las controversias públicas como la historia de Facebook y Cambridge Analytics amenazaron el potencial del marketing de personalidad antes de que realmente haya madurado (Albright, 2016). Es importante no juzgar un campo por sus peores actores. Los profesionales del marketing, comunicadores y el público por igual merecen una mejor comprensión del marketing de la personalidad: qué es, cómo funciona y por qué es importante (Gonzáles, 2017).

Más allá de las acusaciones de uso indebido de información personal obtenida de participantes involuntarios en las redes sociales, la controversia de Cambridge Analytica planteó un aspecto del marketing que pocas personas conocían: la orientación de las personas basada no solo en sus comportamientos pasados y sus preferencias explícitas, pero basado en sus perfiles psicológicos subyacentes (Albright, 2016). "Esto nos permite matizar nuestro mensaje", dijo el CEO de Cambridge Analytics, ante una audiencia de 250 ejecutivos de comunicaciones, seis semanas antes de las elecciones presidenciales de 2016 en los EE. UU. (Graves \& Matz, 2018). Por lo que, en lugar de servir el mismo anuncio a 100 millones de personas, puede subdividir a las personas por personalidad y cambiar la creatividad para que resuene con las personas en función de cómo ven el mundo (Graves \& Matz, 2018).

Más allá de la personalización tradicional basada en datos demográficos o deseos auto expresados por el consumidor, este tipo de personalización 
pretende interpretar los impulsos humanos básicos y relacionar los mensajes de problemas con los rasgos de personalidad; algunos ven la orientación psicométrica o de personalidad como un arte oscuro (Barker, 2018). En este sentido, C. Graves. \& S. Matz. 2018, cita a Cass Sunstein, científico del comportamiento, quien afirma la existencia usos sólidos para los datos personales en las redes sociales si se manejan de manera ética.

La información sobre la personalidad y otros aspectos de la ciencia del comportamiento ofrecen oportunidades para conectarse mejor con las personas, y si se hacen de manera ética, pueden ser beneficiosas para los consumidores y las empresas por igual (Graves \& Matz, 2018). El marketing de la personalidad puede crear una mejor combinación de productos, servicios 0 experiencias (Albright, 2016). Y en sectores como el cuidado de la salud, podría tener efectos aún más positivos, ya que un mejor envío de mensajes conduce a comportamientos más saludables (Graves \& Matz, 2018).

Para los comercializadores, comunicadores e incluso las agencias de salud pública que buscan promover comportamientos más saludables en grandes poblaciones (dieta, nutrición, ejercicio, dejar de fumar), la posible recompensa de usar la ciencia de la personalidad es poder emparejar mejor la forma en que se involucra a los individuos por perfil de personalidad, y para predecir comportamientos por rasgos de personalidad. Ningún vendedor quiere presentar un mensaje fuera de tono o incluso irrelevante; la ciencia de la personalidad ofrece la oportunidad de empatizar con los individuos y comprometerlos con el mensaje, la publicidad o el contenido de una manera que es más probable que resuene con ellos.

\subsubsection{Enfoque moderno de la medición de la personalidad}

Hace solo unos cinco años, el campo recientemente establecido de la ciencia social computacional proporcionó una respuesta: la psicometría digital. En lugar de confiar únicamente en las respuestas de las personas a los cuestionarios auto administrados, los científicos comenzaron a utilizar las huellas digitales de las personas (sus "Me gusta" en Facebook, "Tweets" en Twitter, historiales de navegación y más) para hacer inferencias sobre su personalidad (con su consentimiento).

Los estudios compararon los grupos grandes de respuestas de cuestionarios de personalidad tradicionales de individuos con el 
comportamiento de esas mismas personas en las redes sociales para ver si sus personalidades se podían inferir con precisión simplemente descodificando sus huellas digitales (Díaz \& López, 2015). Basados en grandes conjuntos de datos que contienen las respuestas de ambas personas a los cuestionarios psicométricos tradicionales y la información capturada en sus perfiles de Facebook, los investigadores pudieron identificar relaciones empíricas entre huellas digitales específicas y rasgos psicológicos específicos (Blumer \& Doring, 2012). Por ejemplo, ciertas correlaciones surgieron entre gustar cierto tipo de música o comida y rasgos de personalidad específicos. Cuanto más contenido, más precisa es la evaluación. Al usar los "Me gusta" de los estadounidenses de Facebook (alrededor de 250 "Me gusta", en promedio, en 2012), los algoritmos informáticos fueron mejores para juzgar la personalidad de una persona que sus compañeros de trabajo, amigos e incluso miembros de la familia (Graves \& Matz, 2018).

Aunque todavía está en su infancia, hay cada vez más intentos comerciales de predecir la personalidad a partir de las huellas digitales de las personas. Watson Personality Insights de IBM, por ejemplo, utiliza el procesamiento de lenguaje natural para digerir cuerpos de texto escritos por un usuario específico, como tweets y publicaciones de blog, para descubrir sus rasgos de personalidad, necesidades y valores (Graves \& Matz, 2018). Con el aumento de tales servicios, los conocimientos de la psicometría digital ya no se limitarán a los contextos principalmente académicos, sino que estarán disponibles para la industria en general (Deloitte, 2015).

\subsubsection{Razones para usar el marketing de personalidad y los aspectos éticos}

C. Graves. \& S. Matz. 2018, señalan el caso de los compradores minoristas. A algunos no les gusta especialmente ir de compras, toman un enfoque funcional. Es una tarea, No están ligados a las marcas y están motivados por el precio. Los psicólogos los llaman compradores "utilitarios". Mientras tanto, los compradores "hedónicos" disfrutan comprando, aman las marcas y se unen a programas de lealtad. Se identifican con las marcas y pueden usarlas para señalar quiénes son y qué representan (Mina, 2005). Pueden parecer idénticos cuando se ven a través de los datos demográficos tradicionales, pero estaría muy equivocado al tratarlos de la misma manera. 
Ciertos perfiles de personalidad se correlacionan con compradores utilitarios frente a compradores hedónicos (Mina, 2005). Por lo tanto, si puede conocer las personalidades de los compradores, puede personalizar la forma en que los involucra (Graves \& Matz, 2018).

Pero estos hallazgos no se limitan a las compras minoristas. De hecho, la comunicación personalizada ha demostrado ser altamente exitosa en el contexto de la atención médica y la comunicación para la salud. De acuerdo a Boerebach (2014) diversas investigaciones han evidenciado a las personas que muestran tasas de cumplimiento más altas cuando reciben mensajes que se adaptan a sus motivaciones individuales, y también es conocido que dichos mensajes ayudan a cambiar una serie de comportamientos relacionados con el cáncer, cómo dejar de fumar, realizar dietas y hacer ejercicios. Por ello, C. Graves. \& S. Matz. 2018, se preguntan qué pasaría si no solo fuera posible aumentar las posibilidades de que un cliente compre un bolso, sino que mejoren su calidad de salud o la adopción de vacunas contra la gripe o vacunas al adaptar el mensaje a diferentes personalidades y estilos cognitivos.

La evidencia científica es consistente y clara: se puede aumentar la efectividad de los mensajes de marketing y otros tipos de comunicación persuasiva al adaptarlos a los perfiles psicológicos de las personas (Deloitte, 2015). El problema es que estos resultados provienen principalmente del laboratorio. Por lo tanto, la utilidad de estas ideas para el marketing personalizado en la vida real siguió siendo limitada. El laboratorio no es lo mismo que el mercado, y los cuestionarios no son los mismos que las inferencias de personalidad basadas en datos de Internet. Pero hay razones para creer que la ciencia se mantendrá a escala (Graves \& Matz, 2018).

Sin embargo, a la luz de Cambridge Analytics, C. Graves. \& S. Matz. 2018, afirman que su orientación psicológica inclinó la elección y por ello, era necesario advertir que, contra cualquier afirmación extrema relacionada con el marketing de la personalidad, la evidencia inicial, puede ser prometedora pero el campo todavía es relativamente joven.

Los elementos esenciales de la recopilación y el uso de los rasgos de la personalidad deben seguir las pautas generales de otras investigaciones de la ciencia del comportamiento de los usuarios, empleados o pacientes (Graves \& Matz, 2018). Las implicancias éticas incluyen transparencia de intención y uso; cumplir con las leyes y regulaciones de privacidad; y alinear los intereses del 
investigador / comercializador con los encuestados (en otras palabras, ayudarlos en lugar de explotarlos) (Kamakura, 2011).El último principio es el punto de partida correcto para los profesionales de marketing: ¿El uso de la investigación de la personalidad en realidad está mejorando la vida los clientes, o simplemente los está ayudando? (Kamakura, 2011). A medida que el campo evoluciona, los profesionales del marketing deben buscar en la comunidad de investigación inspiración y orientación sobre la transparencia. Y, por supuesto, las empresas deben cumplir con la ley (Graves \& Matz, 2018). Dada la promesa y la accesibilidad de esta nueva forma de comunicación.

C. Graves. \& S. Matz. 2018, indicaron que el primer paso es comprender el desafío o la meta que intenta alcanzar. Los investigadores plantean un ejemplo inicial: ¿Se trata de alinear a los empleados con los objetivos corporativos, promover el abandono del hábito de fumar, aumentar el uso de vacunas o cambiar el comportamiento del consumidor, o segmentar mejor a los consumidores por lo que realmente los motiva? El siguiente paso consiste en identificar los sesgos cognitivos y las heurísticas que sirven como barreras o impulsoras en el camino hacia el logro de la meta. Debe asignarse los sesgos a los pasos a lo largo del viaje del consumidor (Kamakura, 2011), hacerlo ayudará a identificar los pasos a lo largo de ese viaje donde las comunicaciones creativas o el contenido pueden ayudar a los consumidores a superar sesgos específicos u otros obstáculos para una decisión o un nuevo comportamiento (Graves \& Matz, 2018). Una vez comprendido de forma adecuada el camino del cliente, se puede realizar una prueba de personalidad y combinarla con otros datos para revelar las correlaciones entre los rasgos de personalidad y ciertos comportamientos, preferencias o mentalidades (Graves \& Matz, 2018). El paso final, y el "arte" del marketing de la personalidad, es diseñar los mensajes, la publicidad o el contenido para que coincidan con los diferentes perfiles de la personalidad y, al mismo tiempo, considerar la etapa del viaje del cliente en el que planea participar (Deloitte, 2015). Esto no es fácil, de ninguna manera, pero ofrece la oportunidad de crear el mensaje más eficaz y empático con diferentes grupos de clientes (Graves \& Matz, 2018).

El marketing de la personalidad es solo uno de los aspectos de un nuevo enfoque de rápida comprensión para entender a las personas desde adentro hacia afuera (Kamakura, 2011). Ahora es posible pasar de las rarezas de observación de lo que hace a los humanos "predeciblemente irracionales" (Graves \& Matz, 2018). 


\subsection{Prueba piloto de instrumento}

A fin de probar la validez del instrumento fue necesario realizar una prueba piloto aplicada a 30 personas. Los resultados se muestran a continuación:

Tabla 2: Test de fiabilidad en la prueba piloto

\begin{tabular}{|c|c|}
\hline Cronbach's Alpha & N of Items \\
\hline .812 & 15 \\
\hline
\end{tabular}

El resultado de esta prueba es que el instrumento resulta muy bueno (alpha > 0.80) de acuerdo a M. Takavol. \& R. Dennick. 2011. Hasta aquí, ha sido verificado que el instrumento tiene un grado de fiabilidad.

Pero resulta necesario también aplicar otro tipo de pruebas, como la rotación VARIMAX.

Tabla 3: Matriz de componentes

\begin{tabular}{|l|c|c|c|}
\hline & \multicolumn{3}{|c|}{ Componente } \\
\cline { 2 - 4 } & 1 & 2 & 3 \\
\hline $\begin{array}{l}\text { Se preocupa por otros, } \\
\text { tiene un buen corazón. }\end{array}$ & .866 & & \\
Le interesan las ideas \\
concretas y lógicas. \\
$\begin{array}{l}\text { Es original y tiene ideas } \\
\text { nuevas. }\end{array}$ & .843 & & \\
Es confiable, puede & .841 & & \\
siempre contar conmigo. & .838 & & \\
Está lleno de energía. & .810 & & \\
$\begin{array}{l}\text { Se preocupa mucho por } \\
\text { las cosas. }\end{array}$ & .775 & & \\
$\begin{array}{l}\text { Se fascina por el arte, } \\
\text { música o literatura. }\end{array}$ & .767 & & \\
Tiende a pensar lo mejor \\
de las personas.
\end{tabular}

Elaboración: Propia. 
Tabla 4: Varianza Total Explicada

\begin{tabular}{|c|c|c|c|c|c|c|c|c|c|}
\hline \multicolumn{10}{|c|}{ Varianza total explicada } \\
\hline \multirow[b]{2}{*}{ Componente } & \multicolumn{3}{|c|}{ Autovalores iniciales } & \multicolumn{3}{|c|}{$\begin{array}{l}\text { Sumas de extracción de } \\
\text { cargas al cuadrado }\end{array}$} & \multicolumn{3}{|c|}{$\begin{array}{l}\text { Sumas de rotación de } \\
\text { cargas al cuadrado }\end{array}$} \\
\hline & Total & $\begin{array}{c}\% \text { de } \\
\text { varianza }\end{array}$ & $\begin{array}{c}\% \\
\text { acumulado }\end{array}$ & Total & $\begin{array}{c}\% \text { de } \\
\text { varianza }\end{array}$ & $\begin{array}{c}\% \\
\text { acumulado }\end{array}$ & Total & $\begin{array}{c}\% \text { de } \\
\text { varianza }\end{array}$ & $\begin{array}{c}\% \\
\text { acumulado }\end{array}$ \\
\hline 1 & 6.066 & 40.437 & 40.437 & 6 & & 40.437 & 5.993 & 39.953 & 39.953 \\
\hline 2 & 2.379 & & & & & & 2.377 & & 55.801 \\
\hline 3 & 1.032 & 6.879 & 63.177 & 1.032 & 6.879 & 63.177 & 1.106 & 7.377 & 63.177 \\
\hline
\end{tabular}

Nota: Realizada con método de extracción - análisis de componentes principales

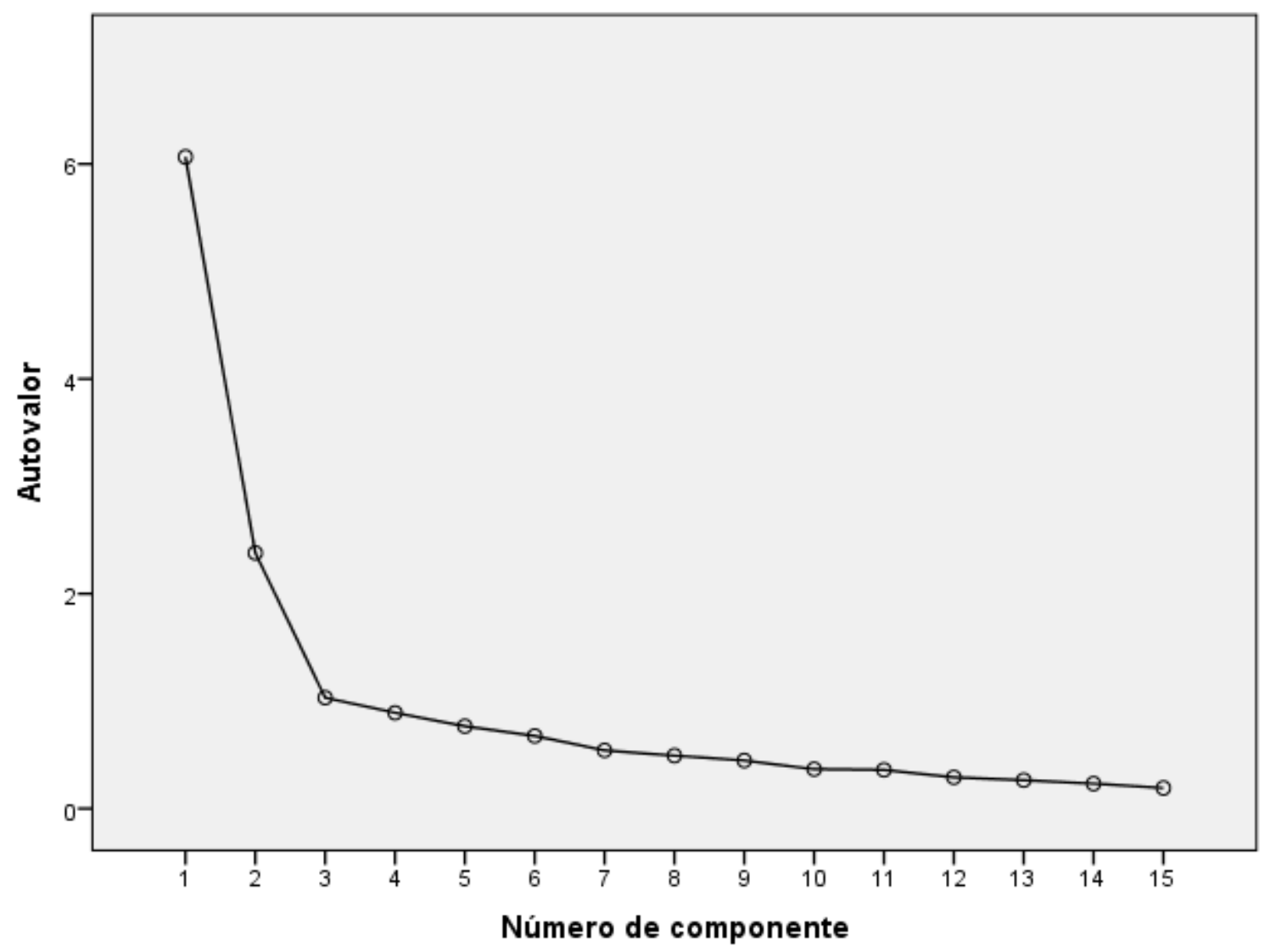

Figura 3: Gráfico de sedimentación para componentes

Existen entonces tres factores de la personalidad que quedan mejor dimensionados que los otros dos restantes. En este caso, solo algunos de los componentes del Big Five deberían ser correlacionados con las preferencias musicales. Estos son: Apertura, Simpatía y Extroversión. Ello es importante debido a que no son considerados todos los elementos del Big Five 


\subsection{Objetivos e Hipótesis}

\subsubsection{Objetivos}

- Objetivo General: Conocer la relación entre el Modelo Big Five de Personalidad y las preferencias musicales de adultos residentes en Lima.

- Objetivo Específico 1: Determinar si el Modelo Big Five de Personalidad es influenciado por el género.

- Objetivo Específico 2: Determinar si las preferencias musicales de los adultos residentes en Lima son influenciadas la edad.

- Objetivo Especifico 3: Determinar si el Modelo Big Five de Personalidad es influenciado por la edad.

\subsubsection{Hipótesis}

- Hipótesis General: Sí hay relación entre el Modelo Big Five de Personalidad y las preferencias musicales en adultos residentes en Lima.

- Hipótesis Especifica 1: El Modelo Big Five de Personalidad sí es influenciado por el género.

- Hipótesis Especifica 2: Las preferencias musicales de los adultos residentes en Lima sí son influenciadas por la edad.

- Hipótesis Especifica 3: El Modelo Big Five de Personalidad sí es influenciado por la edad. 


\section{Metodología}

\subsection{Tipo y Diseño de Investigación}

\subsubsection{Tipo de Investigación}

La investigación es cuantitativa debido a que alcanzará sus objetivos en base al análisis estadístico y matemático de una serie de datos (Hernández, Fernández \& Baptista, 2014). Es una investigación cuantitativa también por el hecho de que se basa en el uso del instrumento que permite medir las variables. En este caso, la investigación busca evidencia matemática de una posible relación entre componentes de la personalidad y el Modelo Big Five.

\subsubsection{Diseño de la investigación}

La investigación es correlacional, no experimental y transversal.

Es correlacional debido a que busca determinar cómo se comporta una variable ante la variación de otra sin que esto necesariamente implique causalidad (Hernández, et.al. 2014). En este caso, parte de la investigación estuvo orientada a correlacionar los componentes de la personalidad y las preferencias musicales.

Es no experimental debido a que en ningún momento los investigadores pretendieron ejercer control alguno sobre las variables 0 aleatorizarlas (Hernández, et.al. 2014). El instrumento, por otro lado, ha sido tomado de una fuente externa.

Es transversal debido a que los datos son recolectados en un momento dado y no se realiza un análisis de las variables a lo largo de diferentes fases (Hernández,et.al. 2014). 


\subsection{Variables}

Tabla 5: Matriz de Variables

\begin{tabular}{|c|c|c|}
\hline Variable & Descripción & Componentes y Operacionalización. \\
\hline $\begin{array}{l}\text { Preferencias } \\
\text { Musicales }\end{array}$ & $\begin{array}{l}\text { Variable dependiente } \\
\text { del estudio. } \\
\text { preferencias las } \\
\text { inventariorara el } \\
\text { peruano planteado por } \\
\text { GFK. Consiste en una } \\
\text { escala de Likert de } 7 \\
\text { puntos. }\end{array}$ & $\begin{array}{l}\text { Basados en los géneros musicales inventarios por GFK } \\
\text { (2017) y referenciado por el especialista en música José } \\
\text { Valverde han sido considerados } 5 \text { géneros: Salsa, cumbia, } \\
\text { rock, reggaetón y el festejo (Ver anexo 3). Se obtiene con } \\
\text { la adaptación del STOMP (una escala ordinal de } 1 \text { a } 7 \text { ) }\end{array}$ \\
\hline \multirow{5}{*}{$\begin{array}{l}\text { Modelo Big } \\
\text { Five }\end{array}$} & \multirow{5}{*}{$\begin{array}{l}\text { Variable independiente } \\
\text { del estudio. Es uno de } \\
\text { los modelos de } \\
\text { personalidadr más } \\
\text { difundidos en el ámbito } \\
\text { científico. }\end{array}$} & $\begin{array}{l}\text { Apertura: Componente independiente de estudio. Describe } \\
\text { la amplitud, profundidad, originalidad y complejidad de la } \\
\text { vida mental y aquella derivada de la experiencia de una } \\
\text { persona. Puede admitir valores de } 3 \text { hasta } 15 \text { (variable } \\
\text { cuantitativa). Operacionalmente se obtiene con el } \\
\text { cuestionario Big Five. }\end{array}$ \\
\hline & & $\begin{array}{l}\text { Neuroticismo: Componente independiente de estudio. } \\
\text { Contrasta la estabilidad emocional y un ánimo estable con } \\
\text { la emocionalidad negativa, tal como sentirse ansioso, } \\
\text { nervioso, triste y tenso. Puede admitir valores de } 3 \text { hasta } 15 \\
\text { (variable cuantitativa). Operacionalmente se obtiene con el } \\
\text { cuestionario Big Five. }\end{array}$ \\
\hline & & $\begin{array}{l}\text { Extroversión: Componente independiente de estudio. } \\
\text { Implica una aproximación energética hacia el mundo social } \\
\text { y material e incluye rasgos como sociabilidad, actividad, } \\
\text { asertividad y emocionalidad positiva. Puede admitir } 5 \\
\text { niveles (variable ordinal). Puede admitir valores de } 3 \text { hasta } \\
15 \text { (variable cuantitativa). Operacionalmente se obtiene con } \\
\text { el cuestionario Big Five. }\end{array}$ \\
\hline & & $\begin{array}{l}\text { Responsabilidad: Componente independiente de estudio. } \\
\text { Describe el control de los impulsos que es prescrito } \\
\text { socialmente y facilita los comportamientos dirigidos al logro } \\
\text { de tareas y metas, como pensar antes de actuar, postergar } \\
\text { las recompensas, seguir normas y reglas, y planear, } \\
\text { organizar y priorizar las tareas. Puede admitir valores de } 3 \\
\text { hasta } 15 \text { (variable cuantitativa). Operacionalmente se } \\
\text { obtiene con el cuestionario Big Five. }\end{array}$ \\
\hline & & $\begin{array}{l}\text { Simpatía: Componente independiente de estudio. } \\
\text { Contrasta una orientación pro social y comunal hacia los } \\
\text { otros con el antagonismo, e incluye rasgos como altruismo, } \\
\text { ternura, confianza y modestia. Puede admitir valores de } 3 \\
\text { hasta } 15 \text { niveles (variable cuantitativa). Operacionalmente } \\
\text { se obtiene con el cuestionario Big Five. }\end{array}$ \\
\hline
\end{tabular}

Nota 1: El Neuroticismo no fue considerado en los objetivos e hipótesis debido a que no ha quedado adecuadamente dimensionado. Situación similar ocurrió con la Responsabilidad.

Nota 2: Tanto el Neuroticismo y la Responsabilidad son descrito, pero para fines académicos 


\subsection{Población}

La población estará conformada por el total de residentes limeños que escuchen música con frecuencia. Fueron considerados aquellos que eran mayores de 18 años.

\subsection{Participantes}

El total de casos válidos ascendió a un total de 384 individuos. Todos ellos participaron de forma voluntaria llenando un cuestionario autoadministrado. Dicho número es base cuando se trabaja con poblaciones que exceden las 100,000 unidades (se asume población infinita).

Tabla 6: Características de la muestra

\begin{tabular}{|l|c|c|c|c|c|c|}
\hline Género & \multicolumn{3}{|c|}{ Masculino } & \multicolumn{3}{c|}{ Femenino } \\
\hline Porcentaje & \multicolumn{3}{|c|}{51.3} & \multicolumn{3}{c|}{48.7} \\
\hline Rango de Edad & $18-22$ & $23-30$ & $31-35$ & $36-40$ & $41-45$ & Más de 46 \\
\hline Porcentaje & 16.9 & 58.3 & 8.1 & 7.3 & 3.6 & 5.7 \\
\hline
\end{tabular}

Fuente: Encuesta Privada

Base: Total de Participantes válidos 384

\subsection{Instrumentos}

\subsubsection{Cuestionario Big Five - Versión Extra Corta (Extra Short)}

De acuerdo P. Costa. \& R. McCrae. 1992, y C. Soto. \& P. John. 2017, las diferencias individuales en los patrones característicos de las personas de pensar, sentir y comportarse se pueden organizar en términos de los dominios del rasgo de personalidad del Big Five. Además, estos cinco amplios dominios pueden ser conceptualizados jerárquicamente, con cada dominio subsumir varios rasgos de faceta más específicos.

Dado que las versiones anteriores del Big Five consistían en 60 preguntas, C. Soto. \& P. John. 2017, indicaron que, en tales situaciones pueden ser necesarias medidas muy breves para evitar la fatiga de los participantes, la frustración y la respuesta descuidada. C. Soto. \& P. John. 2017, también indicaron que algunos estudios de laboratorio pueden desear brevemente evaluar los rasgos de personalidad al mismo tiempo reservando el tiempo tanto como sea posible para las manipulaciones experimentales y observación del comportamiento directa. 
Por lo anterior, la versión extra corta del Big Five. El cuestionario como tal es un subcomponente del cuestionario. La forma del cuestionario Big Five cuenta de una serie de 15 ítems. La distribución de las preguntas está planteada de la siguiente manera: Está distribuido en una escala de Likert que va desde uno hasta cinco (totalmente en desacuerdo - totalmente de acuerdo).

Tabla 7: Cuestionario Big Five Extra Short (Extra corta)

\begin{tabular}{|l|l|}
\hline Componente Big Five & Ítem \\
\hline \multirow{4}{*}{ Apertura } & Se fascina por el arte, música o literatura. \\
\cline { 2 - 2 } & Le interesan las ideas concretas y lógicas. - $\mathrm{R}$ \\
\cline { 2 - 2 } & Es original y tiene ideas nuevas. \\
\hline \multirow{4}{*}{ Reuroticismo } & Se preocupa mucho por las cosas. \\
\cline { 2 - 2 } & Tiende a deprimirse o ponerse triste. \\
\cline { 2 - 2 } & Es emocionalmente estable y no se altera con facilidad. - R \\
\hline \multirow{4}{*}{ Extroversión } & Tiende a ser desorganizado. - $\mathrm{R}$ \\
\cline { 2 - 2 } & Tiene dificultad para iniciar tareas. - $\mathrm{R}$ \\
\cline { 2 - 2 } & Es confiable, puede siempre contar conmigo. \\
\hline \multirow{3}{*}{ Simpatía } & Tiende a ser callado. - $\mathrm{R}$ \\
\cline { 2 - 2 } & Es dominante y actúa como líder. \\
\cline { 2 - 2 } & Está lleno de energía. \\
\hline & Se preocupa por otros, tiene un buen corazón. \\
\cline { 2 - 2 } & Es a veces descortés con los demás. - $\mathrm{R}$ \\
\cline { 2 - 2 } & Tiende a pensar lo mejor de las personas. \\
\hline
\end{tabular}

Fuente: Soto \& John (2017) - Elaboración: Propia.

Nota 1: Los ítems con la letra $R$ significa que la pregunta será puntuada con el puntaje inverso. Es decir, si el encuestado responde 1, entonces deberá ser considerado como 5 para fines del cálculo. Esto de acuerdo a C. Soto. \& P. John. 2017.

Nota 2: El Neuroticismo no fue considerado en los objetivos e hipótesis debido a que no ha quedado adecuadamente dimensionado. Situación similar ocurrió con la Responsabilidad.

Nota 3: Tanto el Neuroticismo y la Responsabilidad son descrito, pero para fines académicos.

\subsubsection{Cuestionario sobre las presencias musicales}

Es un subcomponente del cuestionario. Resulta ser una adaptación del instrumento STOMP de los investigadores P. Rentfrow. \& S. Gosling. 2003. 
Éstos últimos, diseñaron el cuestionario de preferencias para el contexto estadounidense. El participante debe indicar en una escala de likert de 7 puntos su nivel de preferencia por un género específico. A fines de la investigación han sido considerado como parte del inventario musical, las preferencias indicadas por la consultora GFK (2017).

\subsubsection{SPSS}

Es un software que pertenece a IBM (Pallant, 2007). Fue empleado para realizar las pruebas estadísticas que permiten alcanzar el valor de verdad de las hipótesis mediante un conjunto de pruebas estadísticas pertinentes dada la naturaleza de las variables.

\subsection{Procedimiento y Recolección de Datos}

El cuestionario fue trasladado a una versión de Google Forms. Los participantes llenaron de forma voluntario el mismo. El cuestionario incluyó preguntas como el género, la edad y el grado de instrucción. La aplicación Google Forms almacenó todos los datos, los cuales fueron trasladados después a una hoja de cálculo a fin de calcular los valores de cada elemento del Big Five.

De acuerdo a C. Soto. \& P. John. 2017, cada ítem del Extra Short Big Five adopta un valor desde uno hasta cinco. En el caso de los ítems reversos, deberá asignarse el valor opuesto. Así, por ejemplo, si un participantes marcó 1 en el caso del ítem "Tiende a ser desorganizado", el valor final que adquiere como componente del Big Five de personalidad será 5. En el caso de las preferencias musicales, los valores originales son los que serán registrados directamente.

Los datos fueron recolectados en dos periodos. El primero fue de noviembre del 2018 a enero del 2019: la segunda etapa fue realizada entre los meses de abril y mayo del 2019. El control empleado consistió en habilitar un único envío por dispositivo. La recolección terminó cuando se alcanzó los 384 casos válidos necesarios.

\subsection{Plan de análisis}

El cuestionario, previamente, fue sometido a los test de fiabilidad de medida a fin de medir su validez. A modo de complemento, fue empleado la reducción de escalas con rotación de componentes VARIMAX. Luego, las variables de los 
componentes del Big Five fueron correlacionadas con cada una de las preferencias musicales de esta forma, se alcanza el objetivo general.

Con el fin de alcanzar los objetivos específicos de la investigación y dado que se trata de variables se aplican las pruebas de correlación en el caso de la hipótesis general tal como lo hicieron L. Herrera., J. Soares-Quadros. \& O. Lorenzo. 2018, y R. Brown. 2012, para el caso de brasileños y japonseses respectivamente. En el caso de la hipotesis especifica 1 es necesario recurrir a la comparacion de medias. 


\section{Calendario de Actividades y Recursos}

\subsection{Calendario de Actividades}

Las actividades llevadas a cabo para el desarrollo de la tesis fueron los siguientes:

Tabla 8: Cuadro de Actividades

\begin{tabular}{|c|c|c|c|c|c|c|c|c|c|}
\hline Evento & Oct-18 & Nov-18 & Dic-18 & Ene-19 & Feb-19 & Mar-19 & Abr-19 & May-19 & Jun-19 \\
\hline Redacción le borrador de Tesis & $\mathrm{X}$ & & & & & & & & \\
\hline Primera Corrección del borrador & & $\mathrm{X}$ & & & & & & & \\
\hline Aplicación de encuestas & & & $\mathrm{x}$ & $\mathrm{X}$ & $\mathrm{X}$ & & $X$ & $\mathrm{X}$ & \\
\hline Procesamiento de Data & & & & & $\mathrm{X}$ & & $x$ & & \\
\hline Redacción del segundo borrador & & & & & $\mathrm{X}$ & $\mathrm{X}$ & & & \\
\hline Realización de Pruebas Estadísticas & & & & & & $\mathrm{x}$ & & & \\
\hline Redacción y entrega penúltima versión & & & & & & & $X$ & $x$ & \\
\hline Levantamiento de observaciones & & & & & & & & & $\mathrm{X}$ \\
\hline Entrega Final & & & & & & & & & $\mathrm{x}$ \\
\hline
\end{tabular}

Elaboración: Propia. 


\subsection{Recursos Disponibles}

Tanto el cuestionario Big Five (en su versión extra corta) y el STOMP modificado son instrumentos de libre acceso si se usan con fines académicos. La aplicación del cuestionario utilizando Google Forms tampoco tuvo costo alguno. Los investigadores contaban con el instrumento SPSS.

\subsection{Presupuesto}

La investigación no requirió el desembolso de recursos financieros. Esto no significa que no tenga un costo, por el contrario, existe un costo de oportunidad representado por el tiempo dedicado a la investigación que pudo ser invertido en otras actividades. 


\section{Resultados}

\subsection{Resultados}

En primer lugar, es necesario volver a analizar la fiabilidad del instrumento que mide los componentes del Modelo Big Five, pero para los componentes que son objeto de análisis.

Tabla 9: Prueba de Fiabilidad

\begin{tabular}{|c|c|}
\hline Cronbach's Alpha & Numero de Items \\
\hline .892 & 9 \\
\hline
\end{tabular}

El resultado de esta prueba es que el instrumento resulta muy bueno (alpha > 0.80) de acuerdo a M. Takavol. \& R. Dennick. 2011. Hasta aquí, ha sido verificado que el instrumento tiene un grado de fiabilidad.

El siguiente paso consiste en determinar la normalidad de los componentes del Big Five:

Tabla 10: Pruebas de Normalidad

\begin{tabular}{|l|ccc|}
\hline \multicolumn{4}{|c|}{ Pruebas de normalidad } \\
\hline & \multicolumn{3}{|c|}{ Kolmogórov-Smirnov } \\
\cline { 2 - 4 } & Estadístico & gl & Sig. \\
\hline Apertura & .178 & 384 & .000 \\
Extroversión & .119 & 384 & .000 \\
Simpatía & .124 & 384 & .000 \\
Se fascina por el arte, música o literatura. & .255 & 384 & .000 \\
& .338 & 384 & .000 \\
Le interesan las ideas concretas y lógicas. & .339 & 384 & .000 \\
Es original y tiene ideas nuevas. & .189 & 384 & .000 \\
Tiende a ser callado. & .279 & 384 & .000 \\
Es dominante y actúa como líder. & .279 & 384 & .000 \\
Está lleno de energía. & .312 & 384 & .000 \\
Se preocupa por otros, tiene un buen & & & \\
corazón. & .269 & 384 & .000 \\
Es a veces descortés con los demás. & .238 & 384 & .000 \\
Tiende a pensar lo mejor de las personas. & & & \\
& & & \\
\end{tabular}


Debe tomarse en consideración que la prueba Kolmogórov-Smirnov ha sido empleada en lugar Shapiro-Wilk debido a que esta última es empleada para muestras relativamente pequeñas. Los ítems ni las dimensiones del Big Five no tienen una distribución normal. Entonces compete la realización de pruebas no paramétricas. Es por esto, que se usará el coeficiente de correlación de Rho Spearman para la respectiva demostración de la hipótesis general. En caso el nivel de significancia superara el valor de 0.05 , lo adecuado sería emplear la correlación de Pearson. La prueba de correlación fue empleada por L. Herrera. 2018. (Ver Anexo 4).

Tabla 11: Matriz de correlaciones entre preferencias musicales y componentes del Big Five

\begin{tabular}{|c|c|c|c|c|c|}
\hline & & & Apertura & Extroversión & Simpatía \\
\hline \multirow[t]{5}{*}{$\begin{array}{l}\text { Rho de } \\
\text { Spearman }\end{array}$} & Cumbia & $\begin{array}{l}\text { Coeficiente de } \\
\text { correlación } \\
\text { Sig. (bilateral) } \\
\text { N }\end{array}$ & $\begin{array}{c}1688^{* *} \\
.001 \\
384\end{array}$ & $\begin{array}{r}-.051 \\
.319 \\
384\end{array}$ & $\begin{array}{r}153^{* *} \\
.003 \\
384\end{array}$ \\
\hline & Rock & $\begin{array}{l}\text { Coeficiente de } \\
\text { correlación } \\
\text { Sig. (bilateral) } \\
\text { N }\end{array}$ & $\begin{array}{l}.096 \\
.060 \\
384\end{array}$ & $\begin{array}{l}.001 \\
.977 \\
384\end{array}$ & $\begin{array}{l}.044 \\
.390 \\
384\end{array}$ \\
\hline & Salsa & $\begin{array}{l}\text { Coeficiente de } \\
\text { correlación } \\
\text { Sig. (bilateral) } \\
\text { N }\end{array}$ & $\begin{array}{r}, 155^{* *} \\
.002 \\
384\end{array}$ & $\begin{array}{l}, 116^{*} \\
.023 \\
384\end{array}$ & $\begin{array}{r}, 205^{* *} \\
.000 \\
384\end{array}$ \\
\hline & Reggaetón & $\begin{array}{l}\text { Coeficiente de } \\
\text { correlación } \\
\text { Sig. (bilateral) } \\
\text { N }\end{array}$ & $\begin{array}{r}167^{* *} \\
.001 \\
384\end{array}$ & $\begin{array}{r}, 302^{* *} \\
.000 \\
384\end{array}$ & $\begin{array}{r}.214^{* *} \\
.000 \\
384\end{array}$ \\
\hline & Festejo & $\begin{array}{l}\text { Coeficiente de } \\
\text { correlación } \\
\text { Sig. (bilateral) } \\
\text { N }\end{array}$ & $\begin{array}{r}.298^{* *} \\
.000 \\
384\end{array}$ & $\begin{array}{l}.122^{*} \\
.017 \\
384\end{array}$ & $\begin{array}{r}, 263^{* *} \\
.000 \\
384\end{array}$ \\
\hline
\end{tabular}

La tabla anterior, tiene algunas implicancias en el marketing: El nivel de preferencia por la Cumbia, por un lado, solo tiene relación con la Apertura y Simpatía. En cuanto a la Extroversión, no es conveniente emplear dicho elemento para promover la cumbia.

Cabe indicar que, los profesionales del marketing deben considerar que tanto la Apertura, Extroversión y Simpatía no tiene relación con el nivel de preferencia por el 
Rock. Probablemente, el Neuroticismo y la Responsabilidad tengan relación con dicha preferencia musical, al menos para la muestra que estudia a adultos residentes limeños.

La Apertura, Extroversión y Simpatía tienen relación con la Salsa, el Reggaetón y el Festejo. En cuanto a la segmentación basada en la segmentación de personalidad, es necesario tomar en cuenta que existen coincidencias entre las preferencias musicales mencionadas.

Con respecto a la personalidad comparada con el género del participante, los resultados fueron:

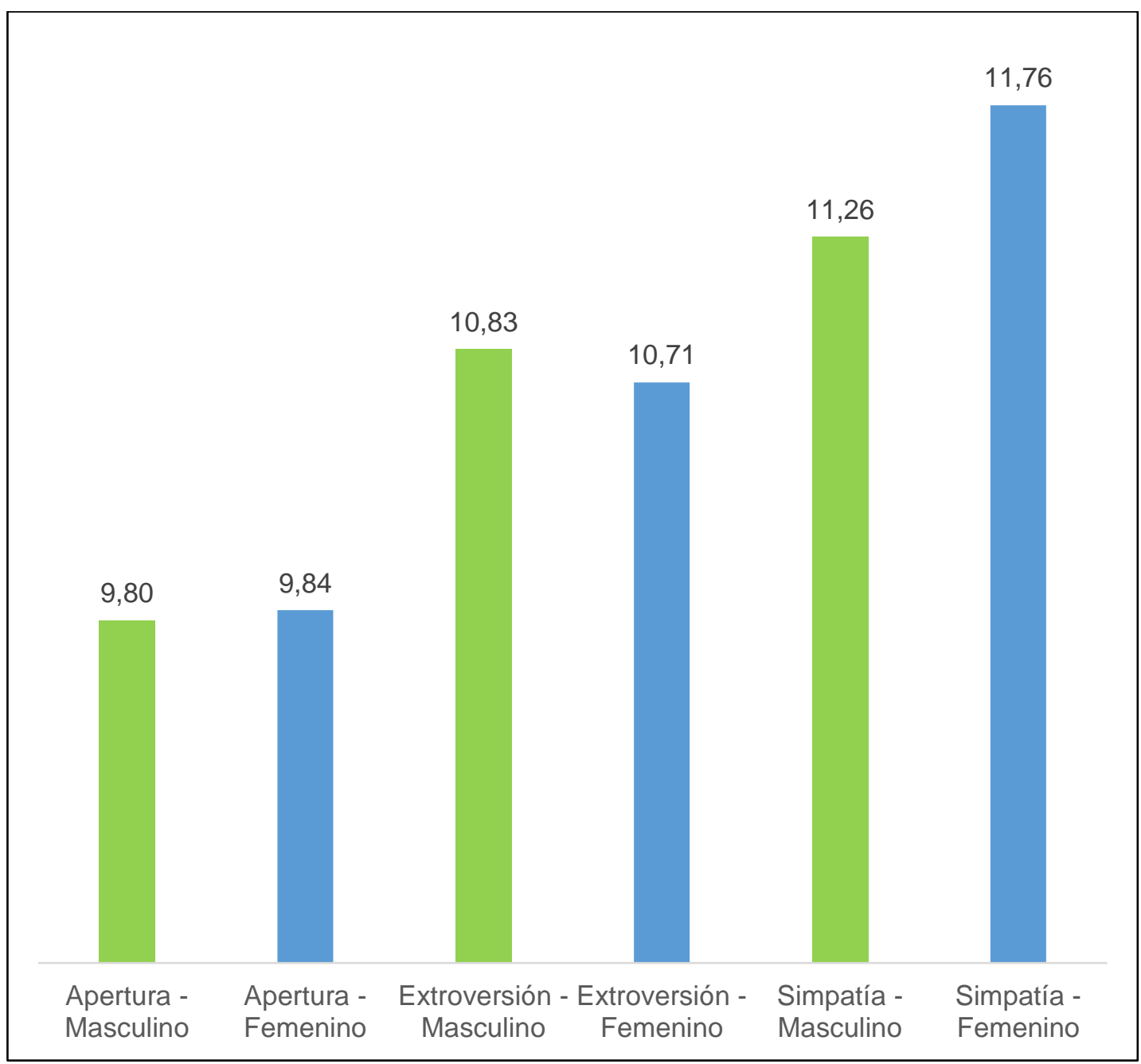

Figura 4: Media de los componentes del Big Five de acuerdo al género del participante

Fuente: Encuesta Privada - Base: Total de participantes (384)

Nota: Es necesario recordar que los puntajes de personalidad se encuentran en el rango de 3 a 15. 
La anterior data solamente es descriptiva. A fin de determinar si el género del participante influye en la personalidad es necesario una prueba estadística. En este caso puede optarse por la prueba $U$ de Mann-Whitney:

Tabla 12: Prueba U de Mann-Whitney- Genero del participante vs. Modelo Big Five

\begin{tabular}{|lr|}
\hline Componente del Big Five & Significancia \\
\hline Apertura & 0.445 \\
Extroversión & 0.401 \\
Simpatía & 0.045 \\
\hline
\end{tabular}

De la tabla anterior, es posible inferir que la simpatía es influenciada por el género del participante en el caso de la simpatía $(0.045<0.05)$. Dicho de otra forma, las mujeres registran niveles de simpatía más altos que los hombres para la muestra analizada. Esto debe ser tomado en cuenta por el marketing debido a que puede ser empleado en campañas promocionales y diseño de mensajes dirigidos al sector femenino donde se debe fortalecer la simpatía.

Lo siguiente a analizar es la relación de dependencia entre el rango de edad, los resultados adoptan la forma planteada por la investigación de B. Ferwerda., M. Schedl. \& M. Tkalcic. 2017, quienes muestran detalles de los datos descriptivos y correlacionales.

Tabla 13: Correlación de la edad con las preferencias musicales

\begin{tabular}{|ll|r|}
\hline Cumbia & Coeficiente de correlación & .013 \\
& Sig. (bilateral) & .803 \\
& $\mathrm{~N}$ & 384 \\
\hline Festejo & Coeficiente de correlación & -.060 \\
& Sig. (bilateral) & .243 \\
& $\mathrm{~N}$ & 384 \\
\hline Reggaetón & Coeficiente de correlación &,- 332 \\
& Sig. (bilateral) & .000 \\
& $\mathrm{~N}$ & 384 \\
\hline Rock & Coeficiente de correlación & .038 \\
& Sig. (bilateral) & .460 \\
& $\mathrm{~N}$ & 384 \\
\hline Salsa & Coeficiente de correlación & -.093 \\
& Sig. (bilateral) & .069 \\
& $\mathrm{~N}$ & 384 \\
\hline
\end{tabular}




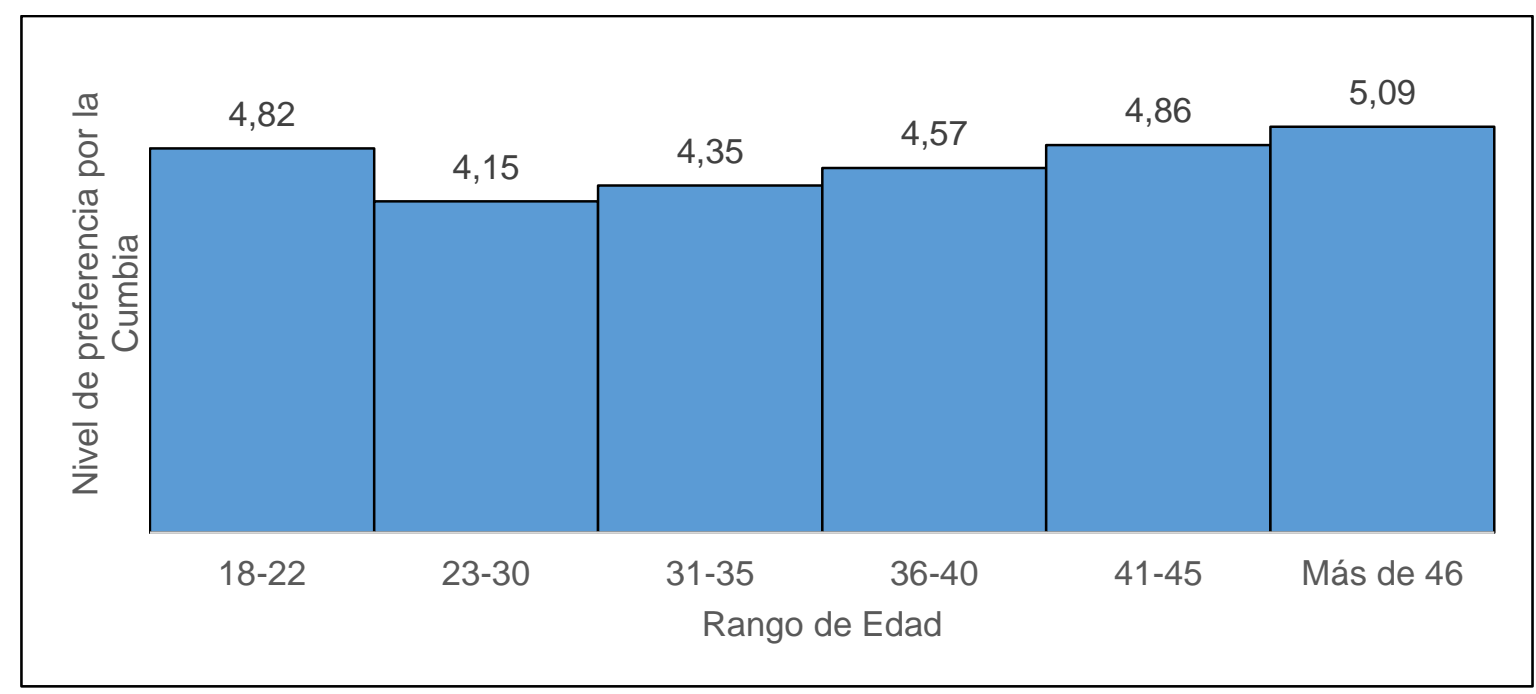

Figura 5: Nivel de preferencias por la cumbia de acuerdo al rango de edad

Fuente: Encuesta Privada - Base: Total de participantes (384)

De la figura anterior, es posible deducir que a partir del rango de entre 23 y 30 años. El nivel de preferencia por la Cumbia se incrementa. Cabe mencionar que, el mayor nivel de preferencia por este género se registra en las personas que tienen más de 46 años.

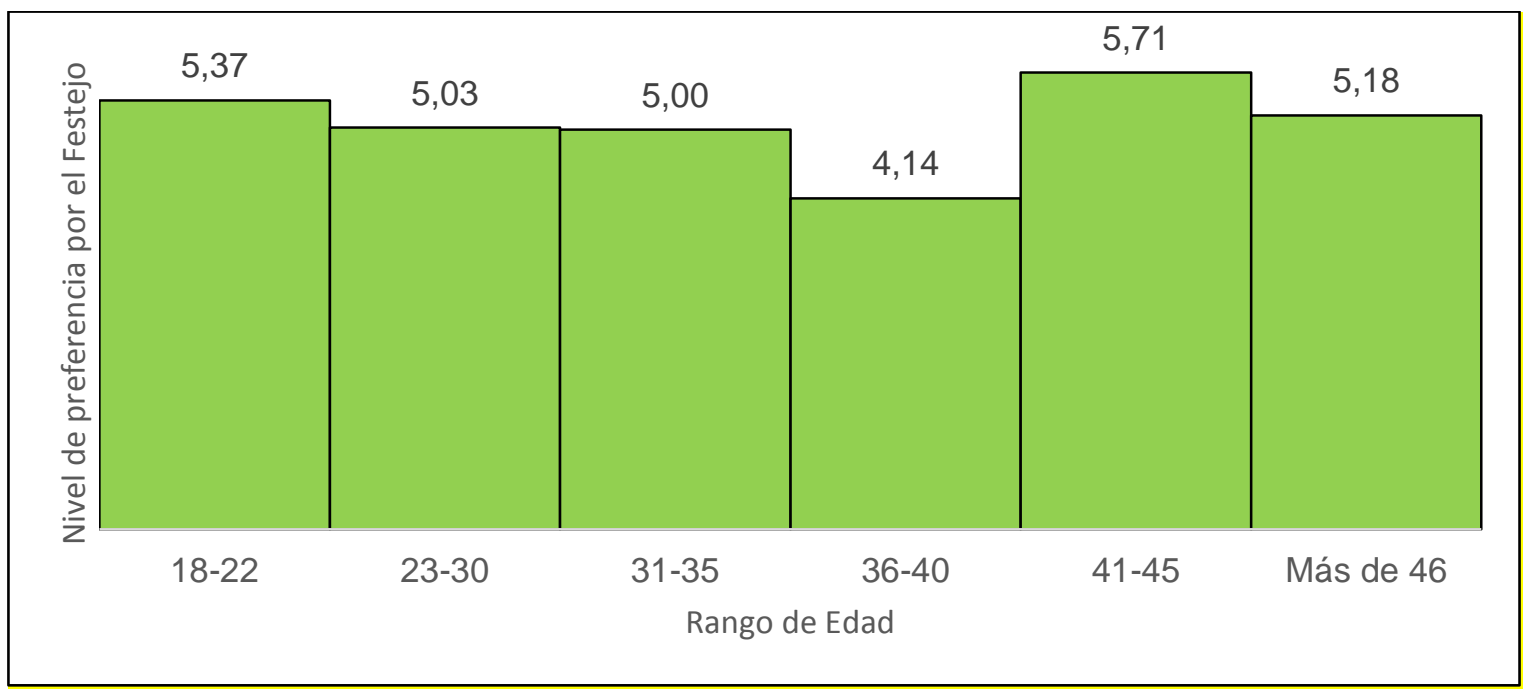

Figura 6: Nivel de preferencias por el Festejo de acuerdo al rango de edad

Fuente: Encuesta Privada - Base: Total de participantes (384)

A partir de los datos de la anterior figura, no existe una tendencia clara en cuanto al nivel de preferencias por el Festejo de cuerdo a la edad. No obstante, el segmento de residentes en Lima entre 41 y 45 años son los que mas prefieren el mencionado género. 


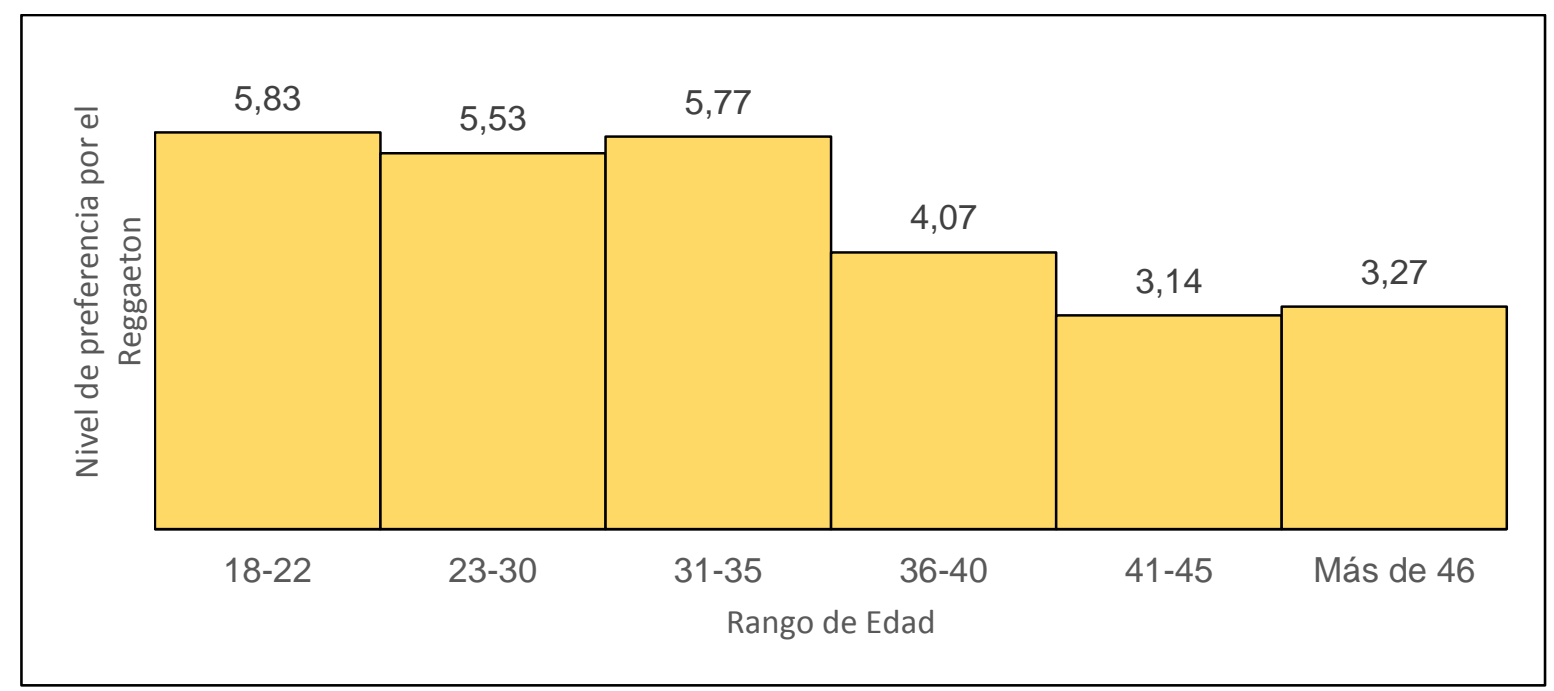

Figura 7: Nivel de preferencias por el Festejo de acuerdo al rango de edad

Fuente: Encuesta Privada - Base: Total de participantes (384)

En cuanto al Reggaetón, los segmentos de menor edad (desde 18 hasta 35 años) alcanzan niveles de preferencia más altos que en los demás. La preferencia por dicho género es mayor en el segmento de entre 18 y 22 años.

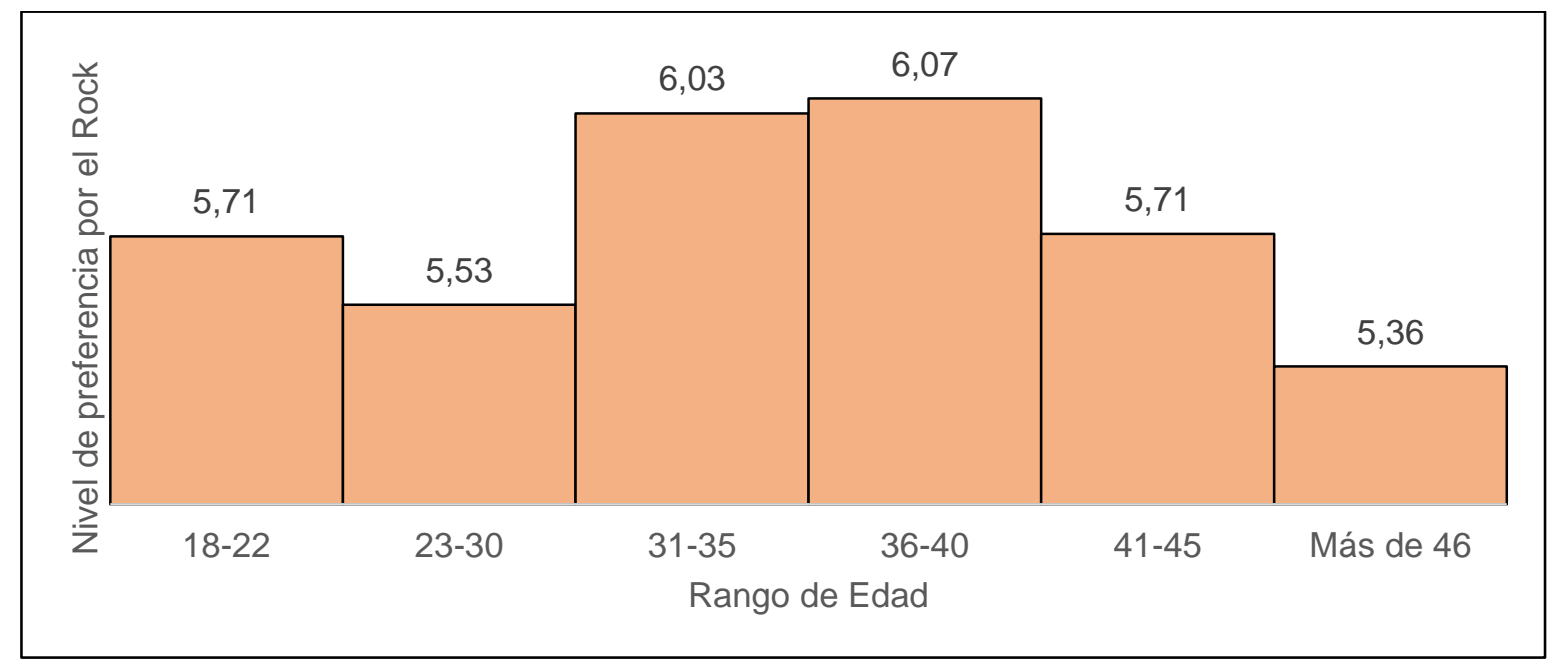

Figura 8: Nivel de preferencias por el Festejo de acuerdo al rango de edad Fuente: Encuesta Privada - Base: Total de participantes (384)

En cuanto al Rock, es posible afirmar que para la muestra estudiada (adultos residentes en Lima) los mayores niveles de preferencia se dan entre quienes tienen desde 31 a 40 años. 


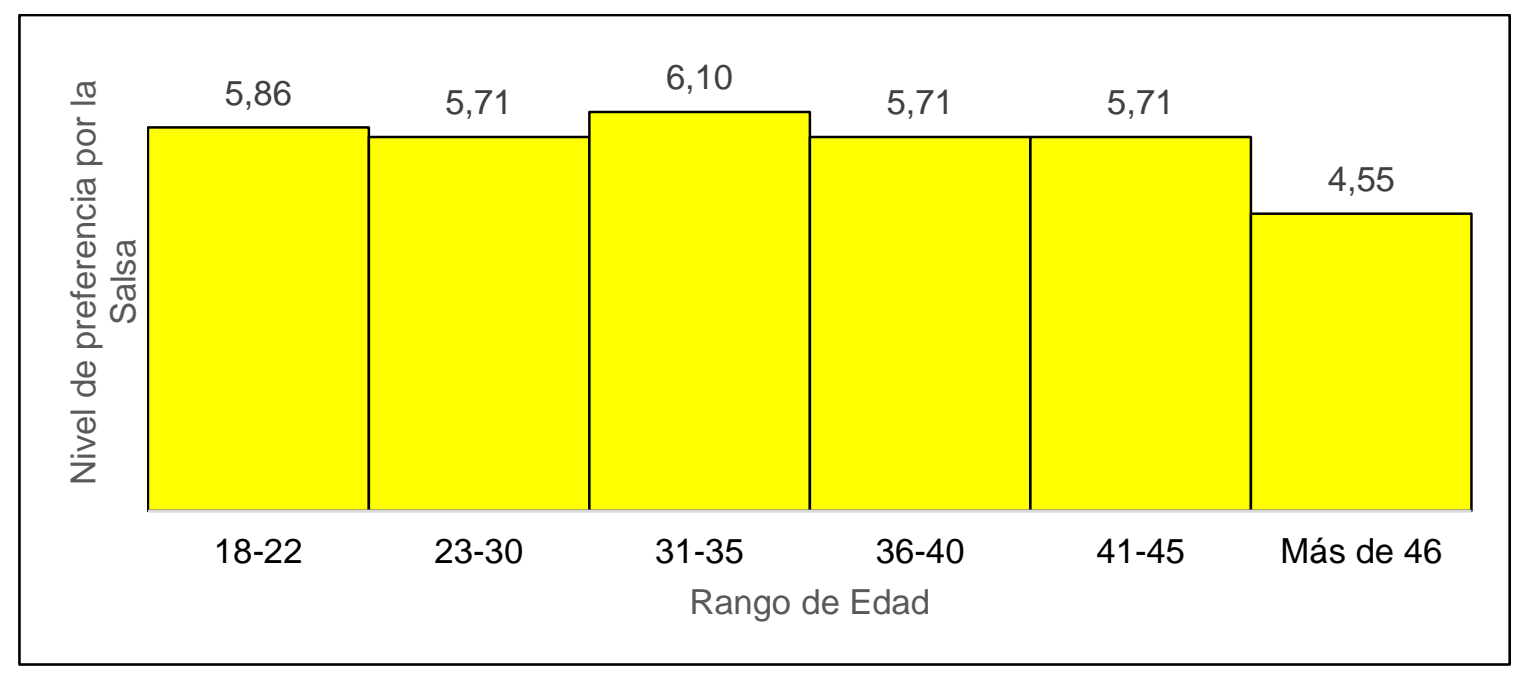

Figura 9: Nivel de preferencias por el Festejo de acuerdo al rango de edad

Fuente: Encuesta Privada - Base: Total de participantes (384)

De la figura anterior, es posible afirmar que el nivel de preferencia por la Salsa es inferior en el segmento de mayor edad (más de 46 años).

Tanto los resultados de la etapa correlacional como en la descriptiva evidencian que las preferencias musicales son independientes del rango de edad para cuatro de los cinco géneros que forman parte del objeto de estudio. El Reggaetón tiene relación con el rango de edad, pero de una forma inversamente proporcional. Ello es importante para el marketing debido a que aquellas estrategias que involucren al Reggaetón pierden efectividad conforme la edad aumenta.

Por otro lado, con respecto a la relación entre los componentes del Big Five de acuerdo al rango de edad, los resultados son los siguientes:

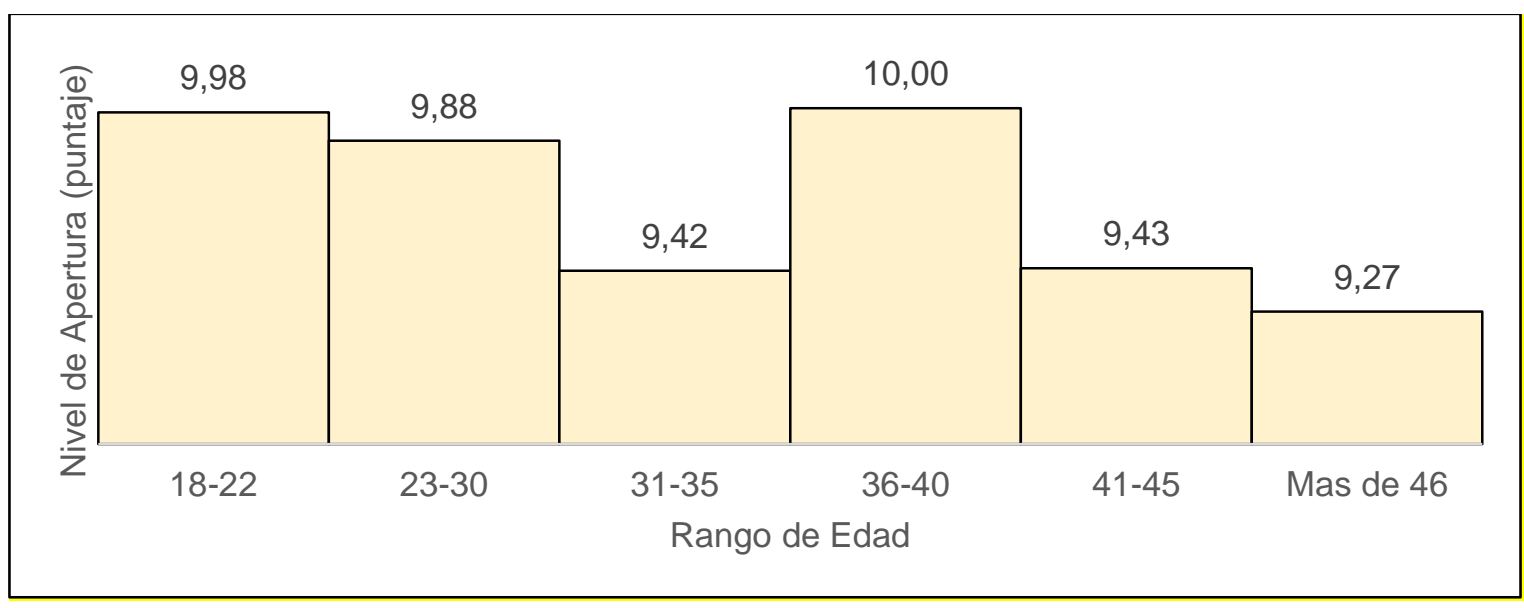

Figura 10: Nivel de Apertura de acuerdo al Rango de Edad

Fuente: Encuesta Privada - Base: Total de participantes (384) 
En base a la figura anterior, existe evidencia de que el nivel de apertura para la muestra estudiada alcanza los valores de mayor cuantía entre quienes tienen de 36 a 40 años.

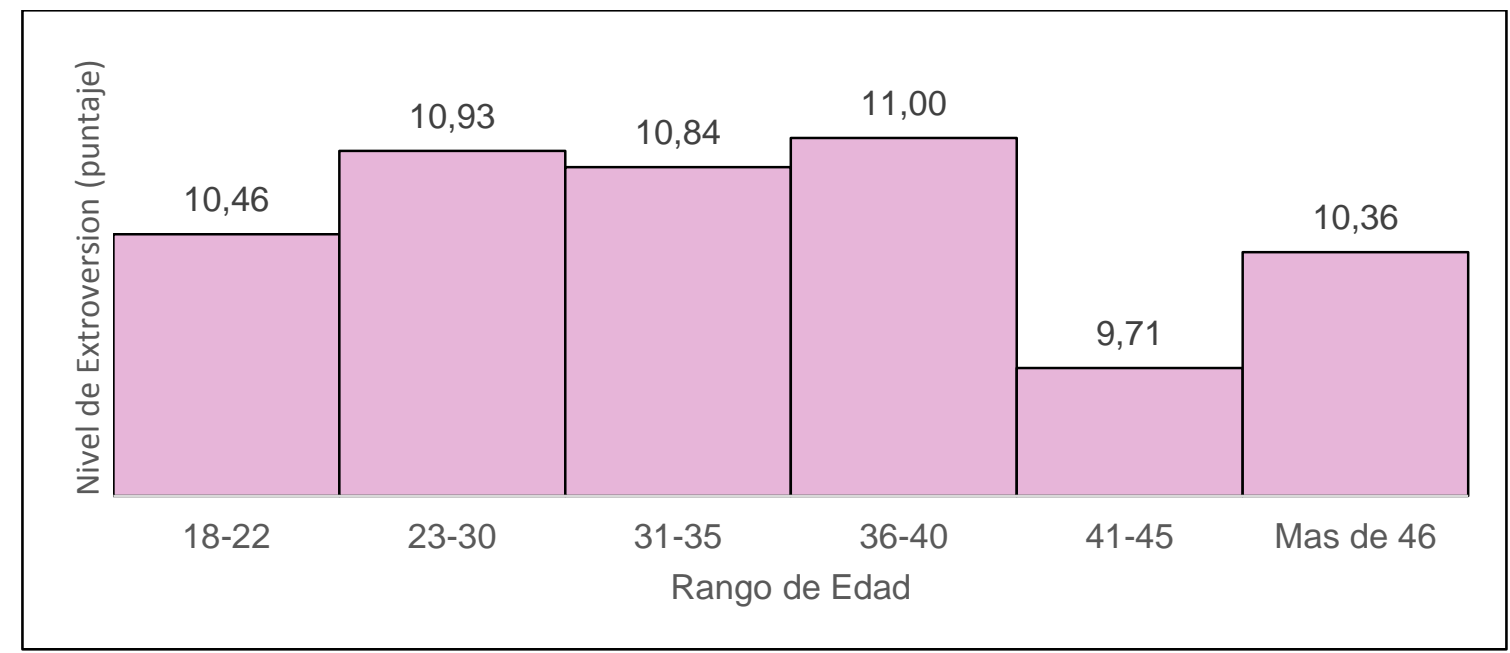

Figura 11: Nivel de Extroversión de acuerdo al Rango de Edad

Fuente: Encuesta Privada - Base: Total de participantes (384)

Con respecto a la Extroversión como componente del Big Five, existe evidencia de que quienes tienen entre 23 y 40 años alcanzan mayores puntajes en cuanto a dicho componentes de la personalidad, al menos en el caso de residentes en Lima.

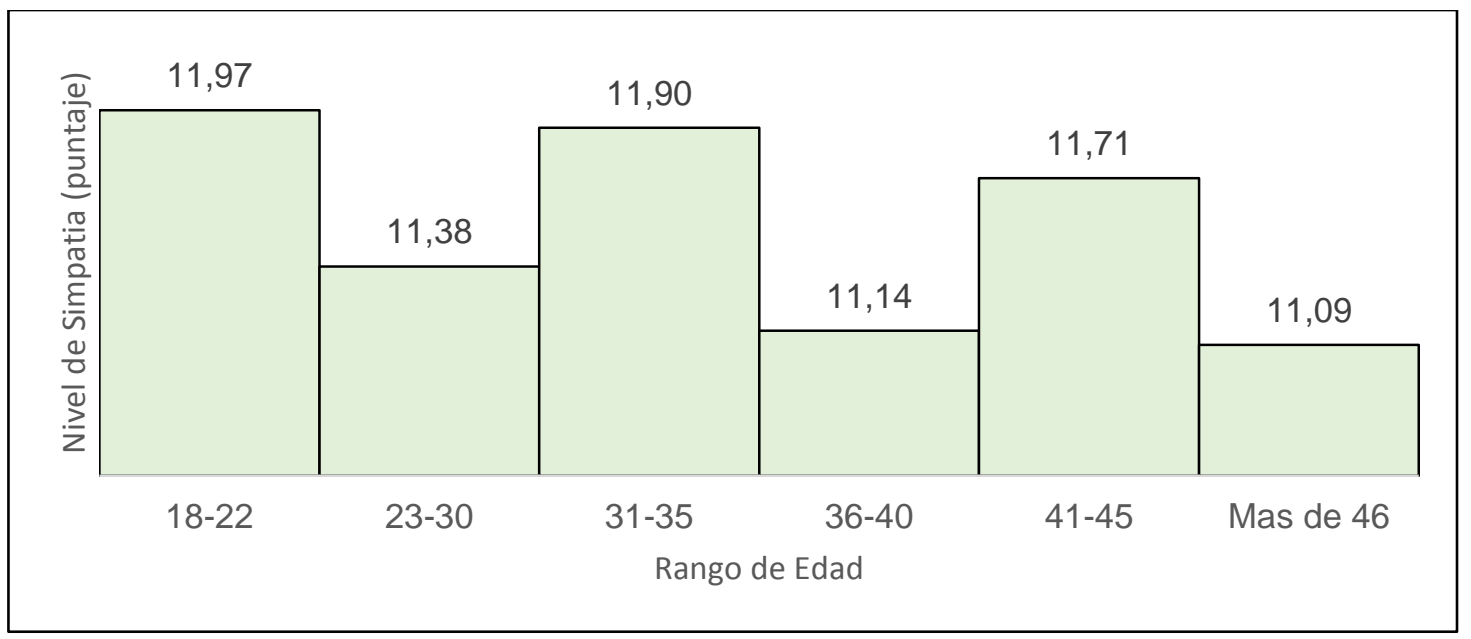

Figura 12: Nivel de Simpatía de acuerdo al Rango de Edad

Fuente: Encuesta Privada - Base: Total de participantes (384) 
De la figura anterior, es posible afirmar que no hay una tendencia en cuanto al pasar de los años y el nivel de Simpatía, al menos para la muestra que es objeto de estudio.

Tabla 14: Correlación entre el rango de edad y el Modelo Big Five

\begin{tabular}{|c|c|c|c|}
\hline & & & Edad \\
\hline \multirow[t]{3}{*}{ Rho de Spearman } & Apertura & $\begin{array}{l}\text { Coeficiente de } \\
\text { correlación } \\
\text { Sig. (bilateral) } \\
\text { N }\end{array}$ & \begin{tabular}{r|}
,$- 158^{* *}$ \\
.002 \\
384
\end{tabular} \\
\hline & Extroversión & $\begin{array}{l}\text { Coeficiente de } \\
\text { correlación } \\
\text { Sig. (bilateral) } \\
\text { N }\end{array}$ & $\begin{array}{r}-.007 \\
.898 \\
384\end{array}$ \\
\hline & Simpatía & $\begin{array}{l}\text { Coeficiente de } \\
\text { correlación } \\
\text { Sig. (bilateral) } \\
\text { N }\end{array}$ & $\begin{array}{r}-.067 \\
.193 \\
384\end{array}$ \\
\hline
\end{tabular}

Los resultados descriptivos y correlacionales evidencias que únicamente la apertura tiene correlación con el rango de edad (.002< 0.05). Dicha relación es inversa. Los profesionales del marketing deben considerar que, en el caso de los residentes limeños, la apertura disminuye conforme aumenta la edad.

\subsection{Discusión}

P. Rentfrow. \& S. Gosling. 2003, encontraron una relación entre Extroversión y preferencias por el Rock. En el estudio realizado difiere de ello pero es similar en el sentido de que este género musical guarda relación con la Simpatía y la Apertura. Los investigadores citados, sin embargo, se centraron más en el Neuroticismo, aspecto que no ha podido ser evaluado adecuadamente para el caso de adultos que residen en Lima, debido a que no ha quedado adecuadamente dimensionado.

E. Vella. \& G. Mills. 2017, incluyeron al rock entre los géneros musicales estudiados Ellos mencionaron que dicho género guarda relación con más de un componente el Big Five, no ocurre lo mismo en el caso de residentes en Lima. Sucede que el Rock no guarda relación ni con la Apertura, ni con la Extroversión y tampoco con la Simpatía.

S. Miranda. 2013, había analizado el caso de los jóvenes estudiantes chilenos de escuela secundaria. El investigador indicó que la edad era una variable que 
influenciaba los rasgos de la personalidad. En este sentido, los hallazgos coindicen únicamente para la Apertura. La relación es inversa.

D. Tully. 2012, había mencionado que dos rasgos de la personalidad (Apertura y Extroversión) guardaban relaciones considerables con el inventario musical propio del STOMP en el caso de los estudiantes universitarios de Dublín. En el caso de la investigación aplicada a residentes limeños, dichos componentes también tienen correlación con las preferencias musicales. Pero no para todos, sino para algunos. De los 5 géneros estudiados solo uno no tiene relación con los componentes de la personalidad adecuadamente dimensionados: el Rock.

L. Herrera. 2018, indicó que la escucha musical de los participantes de Brasil se limita a un número reducido de estilos, principalmente música pop y otros típicos de la cultura brasileña. En el caso de la investigación que incluye a residentes en Lima, el pop ha sido considerado como objeto de estudio. En cambio, de acuerdo a lo indicador por GFK (2017) y por el experto José Valverde, existen 5 géneros representativos para comprender al residente limeño: Cumbia, Rock, Salsa, Reggaetón y Festejo.

L. Herrera. 2018, también indicó que existe una correlación entre la mayoría de los tipos de personalidad analizados y los estilos musicales latino, brasileño, clásico y étnico. En el caso de los residentes limeños y dado los cinco géneros musicales objeto de estudio (Cumbia, Rock, Salsa, Reggaetón y Festejo), únicamente el Rock no tiene relación con algunos de los componentes del Big Five. Cabe mencionar que el Festejo, como música originaria del Perú tiene correlación con todos los componentes del Big Five. 


\section{Conclusiones y Recomendaciones}

\subsection{Conclusiones}

- $\quad$ En cuanto a la hipótesis general se ha comprobado que algunos de los componentes de la personalidad bajo el modelo Big Five guardan relación con las preferencias musicales de los residentes en Lima. Estas relaciones son predominantemente del tipo directa. Las dimensiones del Big Five que guardan relación con las preferencias musicales son Simpatía, Extroversión y Apertura. La hipótesis general, entonces, es verdadera.

- Lo anteriores tiene algunas implicancias en el marketing: el nivel de preferencia por la cumbia, por un lado, solo tiene relación con la apertura y simpatía. En cuanto a la extroversión, no es conveniente emplear dicho elemento para promover la cumbia. Por otro lado, el festejo si tiene correlación con todos los componentes del Big Five que fueron objeto de análisis.

- La evidencia muestra que no es adecuado correlacionar a los otros dos componentes del Big Five (Neuroticismo y Responsabilidad) con las preferencias musicales del público objetivo debido a que no quedan adecuadamente dimensionadas.

- $\quad$ Con respecto a la hipótesis específica 1, resulta verdadero que el Modelo Big Five de Personalidad sí es influenciado por el género. No obstante, ello únicamente ocurre para la simpatía. Las mujeres alcanzan niveles de simpatía significativamente más altos que los hombres en el caso de los adultos que residen en Lima. Esto debe ser tomado en cuenta por el marketing debido a que puede ser empleado en campañas promocionales y diseño de mensajes dirigidos al sector femenino donde se debe fortalecer la simpatía.

- $\quad$ Con respecto a la hipótesis específica 2, aquella que indica que las preferencias musicales de los adultos residentes en Lima son influenciadas por la edad, resulta verdadera en el caso del Reggaetón. Ello es importante para el marketing debido a que aquellas estrategias que involucren al reggaetón pierden efectividad conforme la edad aumenta. No hay evidencia de correlaciones significativas en los otros géneros musicales. 
- $\quad$ En lo relacionado a la hipótesis específica 3, aquella que postulaba que el Modelo Big Five de Personalidad sí es influenciado por la edad, resulta ser cierta pero únicamente para la apertura: a medida que el rango de edad se incrementa, los residentes limeños que forman parte de la muestra tienden a presentar menores niveles de dicho rasgo de la personalidad.

\subsection{Recomendaciones}

\subsubsection{Teóricas}

- $\quad$ Comparar la fiabilidad del instrumento Extra short Big Five con otras versiones de mayor extensión a fin de comprobar la validez y el correcto dimensionamiento de los componentes de la personalidad.

- $\quad$ La validez del cuestionario Big Five puede verificarse de otras formas. Algunos papers estadounidense tienden a incluir preguntas que invalidan un instrumento. Así, por ejemplo, un ítem que diga "Marque totalmente de acuerdo" puede ser introducido. Si el participante no marca esa opción significa que no está completando apropiadamente el instrumento. Este mecanismo podría ser incluido con el fin de comparar si de alguna manera la extensión de los cuestionarios Big Five termina afectando las respuestas del participante.

\subsubsection{Prácticas}

- Desde una perspectiva práctica, los resultados del estudio deben ser tomados en cuenta por los profesionales del marketing a fin de diseñar mensajes promocionales. En el caso de los adultos residentes en Lima, el Rock, por ejemplo, tiene una preferencia considerable, no obstante, no guarda relación con los componentes Big Five como la Apertura, Extroversión y Simpatía.

- En lo que a diseño de mensajes promocionales y construcción de campañas se refiere, existe evidencia de que el Reggaetón, el Festejo y la Cumbia guardan relación con la Apertura, Extroversión y Simpatía. Es probable que mensajes que coincidan con dichos componentes de la personalidad generen un mayor nivel de aceptación entre los receptores.

- $\quad$ El Neuroticismo y la Responsabilidad no deben ser descartados por los profesionales del marketing en lo que a la industria musical se refiere. Ciertamente deben existir algunas preferencias musicales que guardan relación con dichos componentes de la personalidad, pero para ello se requiere 
estudios más profundos, probablemente con un instrumento con mayor número de ítems.

- $\quad$ En el caso de la Salsa hay dos elementos de la personalidad que deben ser aprovechados la Simpatía y la Apertura. Esto es quizás algo que deben considerar las empresas productoras de contenido musical y también las radiodifusoras. Esto claro si el objetivo es hacer que dicho género musical genere más engagement con el residente limeño. 


\section{Limitaciones e Investigaciones Futuras}

\subsection{Limitaciones}

Una de las limitaciones importantes del estudio es la presencia de variables que no han sido consideradas. De acuerdo a lo señalado por S. Miranda. 2013, existen importantes variables extrañas como las mismas características socio-demográficas de cada individuo, la estructura familiar, el grupo de pares con el que se relaciona, las creencias en las que basa su comportamiento. Limitaciones de este tipo también habían sido mencionadas por R. Brown. 2012. Naturalmente, sería deseable obtener todas esas variables, pero resultaría poco viable.

Otro limitación para este tipo de estudios, como bien señala M. Langemeyer. 2012. Radica en que es muy probable que la relación entre la personalidad y las preferencias musicales esté determinada por otros indicadores personales, como la edad y los antecedentes personales. Por ejemplo, alguien a quien le gusta la música rap y tiene 20 años de edad puede tener una personalidad diferente a la de alguien que tiene 60 años y (aún) es un fanático del mismo género. En futuras investigaciones, sería preferible una muestra ampliada y diferenciada para ayudar a generalizar los hallazgos.

\subsection{Investigaciones Futuras}

Anteriormente ya se había mencionado que existía la posibilidad de realizar un modelo Big Five computarizado utilizando el contenido de las redes sociales. Esta técnica bien podría ser combinada con un cuestionario de preferencias musicales. De esta manera es posible correlacionar las preferencias declaradas con la huella digital.

Existen instrumentos como Watson Personality Insights que permiten determinar no solo los componentes del Big Five, sino que además también cuantifican las preferencias musicales (Ver Anexo 7). Una línea de investigación a futuro consistiría en enviar cuestionarios Big Five y de preferencias musicales a usuarios de redes sociales. De esta forma, sería posible realizar un comparativo entre los resultados digitales versus los reales.

Las preferencias musicales pueden ser expresadas también como una respuesta única. De esta forma podría emplearse un modelo de regresión logística en donde la variable dependiente sería el género musical preferido. Esto implica también que la muestra sea de mayor tamaño. 
El instrumento original de preferencias musicales STOMP puede ser ajustado a las preferencias musicales peruanas. Pero para ello sería necesario contar con una muestra con un considerable grado de representatividad (aleatoria). De esta forma podrían ser construidas dimensiones similares a las del STOMP, ajustadas a las preferencias musicales que forman parte de la realidad peruana. 


\section{Bibliografía}

Albright, J. (2016). How Trump's campaign used the new data-industrial complex to win the election. London School of Economics. Retrieved Noviembre 3, 2018, from http://eprints.Ise.ac.uk/69110/1/blogs.Ise.ac.ukHow\%20Trumps\%20campaign\%20used\%20the\%20new\%20dataindustrial\%20complex\%20to\%20win\%20the\%20election.pdf

Alizadeh, M., \& Weber, I. (2014). Psychological and Personality Profiles of Political Extremists. Retrieved Febrero 2, 2017, from https://arxiv.org/abs/1704.00119

Amichai, Y., \& Vinitsky, G. (2010). Social network use and personality. Computers in Human Behavior, 26, 1289-1295.

Arkeelin, D. (2014). Using SPSS to Understand Research and Data University. Valparaiso Univeristy. Retrieved from http://scholar.valpo.edu/cgi/viewcontent.cgi?article=1000\&context=psych_oer

Barker, M. (2018). Cambridge Analytica, 'Nudge Theory', and 'figures of the audience'. Participations-Journal of Audience \& Reception Studies, 15(1).

Berger, G. (1977). Carácter y personalidad. Buenos Aires: Paidós.

Berna, A. (2012). Análisis exploratorio de la publicidad en Facebook y Twitter. Retrieved from http://webquery.ujmd.edu.sv/siab/bvirtual/BIBLIOTECA\%20VIRTUAL/TESIS/03/ DPA/ADTESUU0001492.pdf

Blumer, T., \& Doring, N. (2012). Are we the same online? The expression of the five factor personality traits on the computer and the Internet. Journal of Psychosocial Research on Cyberspace, 6(3). doi:10.5817/CP2012-3-5

Boerebach, B. (2014). The impact of clinicians' personality and their interpersonal behaviors on the quality of patient care: a systematic review. International Journal of Quality of Health Care, 426-481. doi:10.1093/intqhc/mzu055

Bonneville-Roussy, A. (2014). There is accounting for taste: Determinants of musical taste in adulthood (Unpublished doctoral thesis). University of Cambridge, Cambridge, UK.

Brown, R. (2012). Music preferences and personality among Japanese university students. 47(4), 259-268. doi:10.1080/00207594.2011.631544 
Cattell, R., \& Saunders, D. (1954). Musical preferences and personality diagnosis. Journal of Social Psychology, 39(1), 3-24.

Chamorro-Premuzic, T., Swami, V., Furnham, A., \& Maakip, I. (2009). Journal of Individual Differences. The Big Five Personality Traits and Uses of Music - A Replication in Malaysia using Structural Equation Modeling, 30(1), 20-27.

Cleridou, K., \& Furhnham, A. (2014). Personality correlates of aesthetic preferences for art, architecture and music. Empirical Studies of the Arts, 32(2), 231-255.

Cohen, J. (1980). Evaluación de la personalidad. Mexico DF: Trillas.

Costa, P., \& McCrae, R. (1992). Revised NEO Personality Inventory (NEO-PI-R) and NEO Five-Factor Inventory (NEO-FFI) Manual. In Psychological Assessment Resources.

Culotta, A., \& Cutler, J. (2016). Mining Brand Perceptions from Twitter Social Networks. Marketing Science. doi:10.1287/mksc.2015.0968

Deloitte. (2015). Disruption ahead: Deloitte's point of view on IBM Watson. Retrieved from https://www2.deloitte.com/content/dam/Deloitte/us/Documents/aboutdeloitte/us-ibm-watson-client.pdf

Díaz, H., \& López, R. (2015). "Estudiando la validez de IBM Watson Personality Insights en una muestra de estudiantes FEN como un acercamiento al perfil de cargo para la selección de personal. Tesis de grado, Universidad de Chile, Santiago.

Fast, L., \& Funder, D. (2008). Personality as manifest in word use: correlations with self-report, acquaintance report, and behavior. Journal of Personality and Social Psychology, 94(2), 334-346.

Ferwerda, B., Schedl, M., \& Tkalcic, M. (2017). Personality traits and music genre preferences: How music taste varies over age groups. CEUR Workshop Proceedings: RecTemp 2017 Temporal Reasoning in Recommender Systems. Retrieved junio 22, 2019, from http://ceur-ws.org/Vol-1922/paper4.pdf

Garth, A. (2008). Analysing data using SPSS. Retrieved Febrero 22, 2017, from Sheffield Hallam University: http://teaching.shu.ac.uk/hwb/ag/resources/material/analysingdatausingspss.pd f 
Gaytán, P. (2001). Desmodernos: Crónica suburpunk de algunos movimientos culturales en la submetrópoli defeña. Toluca: Universidad Autónoma de México.

GFK. (2017). Las preferencias musicales y los peruanos. Retrieved Junio 21, 2018, from

https://www.gfk.com/fileadmin/user_upload/country_one_pager/PE/documents/ GfK_Opinio_n_Enero_2017-_Los_peruanos_y_la_musica_2.pdf

Golbeck, J., Robles, C., Edmodson, M., \& Turner, K. (2011). Predicting Personality from Twitter. Retrieved from https://pdfs.semanticscholar.org/8a6d/ca55d8fabd15bec20eb25a5614172de16 4a7.pdf

Goldberg, L. (1992). The development of markers for the Big-five factor structure. Psychological Assessment., 4(1), 26-42. doi:10.1037/1040-3590.4.1.26

Gonzáles, R. (2017). Hacking the citizenry? Personality profiling, 'big data' and the election of Donald Trump. Working Paper, Yale University, Department of Computer Science. Retrieved Noviembre 5, 2018, from http://www.cs.yale.edu/homes/jf/Gonzalez.pdf

Graves, C., \& Matz, S. (2018). What Marketers Should Know About Personality-Based Marketing. (H. B. Review, Ed.) Retrieved Enero 22, 2019, from https://hbr.org/2018/05/what-marketers-should-know-about-personality-basedmarketing

Greasley, A. (2008). Engagement with music in everyday life: An in-depth study of adults' musical preferences and listening behaviour. 7th Triennial Conference of European Society for the Cognitive Sciences of Music. University of Keele. doi:10.1177/1029864910393417

Greasley, A., Lamont, A., \& Sloboda, J. (2013). Exploring musical preferences: an indepth qualitative study of adults' liking for music in their personal collections. Qualitative Research in Psychology, 402-427. doi:10.1080/14780887.2011.647259

Gregory, A. (1997). The roles of music in society: The ethnomusicological perspective. Retrieved Febrero 14, 2018, from https://www.researchgate.net/publication/232489005_The_roles_of_music_in_s ociety_The_ethnomusicological_perspective 
Hargreaves, D. (1998). Música y desarrollo psicológico. Barcelona: GRAO.

Hernández, R., Fernández, C., \& Baptista, P. (2014). Metodología de la Investigación (Quinta ed.). México: McGraw Hill.

Herrera, L., Soares-Quadros, J., \& Lorenzo, O. (2018). Music Preferences and Personality in Brazilians. Frontiers in Psichology, 21(9), 1488-1492. doi:10.3389/fpsyg.2018.01488

IBM. (2016). Personality Insights - La ciencia detrás del servicio. Retrieved from https://console.bluemix.net/docs/services/personalityinsights/science.html\#science

IBM. (2019). Personality Insights Demo. Retrieved Junio 18, 2019, from https://personality-insights-demo.ng.bluemix.net/

Janasik, N., Honkela, T., \& Bruun, H. (2009). Text Mining in Qualitative Research Application of an Unsupervised Learning Method. Organizational Research Methods, 12(3), 436-460.

Ji, Q., \& Raney, A. (2014). ). Morally judging entertainment: A case study of live Tweeting during Downton Abbey. Media Psychology, 18, 221-242.

Jin, A., \& Phua, J. (2014). Following Celebrities' Tweets About Brands: The Impact of Twitter-Based Electronic Word-of-Mouth on Consumers' Source Credibility Perception, Buying Intention, and Social Identification With Celebrities. Journal of Advertising, 43(2).

Kalampokis, E. (2013). Understanding the predictive power of social media. Internet Research, 23, 544-559.

Kamakura, W. (2011). Marketing Research. Wiley.

Khriyenko, O., Nguyen, C., \& Marek, P. (2016). IBM Watson. MIT . Retrieved from http://users.jyu.fi/ olkhriye/IBM/IBM_Watson.pdf

Kumar, S., Morstatter, F., \& Liu, H. (2014). Twitter Data Analytics. Springer.

Lafuerza, N. (s.f.). Como desarrollar la personalidad. Buenos Aires: Instituto Lafuerza.

Langemeyer. (2012). )What do music preferences reveal about personality? A crosscultural replication using self ratings and ratings of music samples. Journal of Individual Differences, 39(2), 199-130. doi:10.1027/1614-0001/a000082 
Lemos, V. (1997). Rasgos de personalidad asociados con la ejecución de determinados instrumentos musicales. Entre Rios: Universidad Adventista del Plata.

López, J. (s.f.). Evidencia histórica, experimental y psicológica de la acción de la música sobre los seres vivos. Musicoterapia. Madrid, España.

Maddi, S. (1972). Teorías de la personalidad, un análisis comparativo. Buenos Aires: Librería El Ateneo Editorial.

Maffesoli, M. (1996). The Time of the Tribes The Decline of Individualism in Mass Society. Paris: Sage.

Mina, E. (2005). Justification Effects on Consumer Choice of Hedonic and Utilitarian Goods. Journal of Marketing Research, 42(1), 43-53.

Miranda, S. (2013). Rasgos de la personalidad asociados al estilo musical por adolescentes estudiantes de nivel secundario. Tesis de pregrado, Universidad de Chile, Facultd de Ciencias Sociales. Retrieved Diciembre 22, 2018, from http://repositorio.uchile.cl/bitstream/handle/2250/115416/2.\%20Resumen.pdf?s equence $=2 \&$ is Allowed $=y$

Mottini, G. (1944). Con siete notas. Barcelona: Luís de Caralt.

Nave, G., \& Kosinski, M. (2018). Musical Preferences Predict Personality: Evidence from Active Listening and Facebook Likes. Psychological Science. doi:10.17863/CAM.21182

Norman, W. (1963). Toward an adequate taxonomy of personality attributes: Replicated factor structure in peer nomination personality rating. Journal of Abnormal and Social Psychology, 66(6), 574-583.

North, A., \& Hargreaves, D. (2009). The power of music. The Psychologist, 22, $1012-$ 1024.

Ogini, O., Odofile, M., Odusanmi, D., \& Taiwo, A. (2015). Awareness and Response to Human Immunodeficiency Virus / Acquired Immune Deficiency Syndrome (HIV/AIDS) among University Students in Abeokuta, Nigeria. Public Health Research, 5(6), 192-197.

Ozbag, G. (2016). The Role of Personality in Leadership: Five Factor Personality Traits and Ethical Leadership. In Procedia. doi:10.1016/j.sbspro.2016.11.019

Pahissa, J. (1954). Los grandes problemas de la música. Buenos Aires: Americana. 
Pallant, J. (2007). SPSS survival manual: a step by step guide to data analysis using SPSS for Windows. Open University Press.

Piaget, J. (1991). Seis Estudios de Psicología. Barcelona, España: Ariel.

Quiñones, C. (2008). Desnudando la mente del conusmidor: Consumer Insights en el Marketing. Lima: Planeta.

Ramírez, J. (2006). Música y sociedad: la preferencia musical como base de la identidad social. Sociológica, 21(60), 243-270.

Raney, A. (2009). Handbook of Sport Media. New York: Laurence Eribaum Associates.

Rentfrow, P., \& Gosling, S. (2003). The do re mi's of everyday life: The structure and personality correlates of music preferences. Journal of Personality and Social Psychology, 84(6), 1236-1256. doi:10.1037/0022-3514.84.6.1236

Romero, J., Dafonte, C., \& Gómez, A. (2007). Inteligencia Artificial y Computación Avanzada. Santiago de Compostela: Fundación Alfredo Brañas .

Rowell, L. (1985). Introducción a la filosofía de la música. Antecedentes históricos y problemas estéticos. Barcelona: Gedisa.

Sepúlveda, G. (2001). Autonomía Moral y Solidaridad: Complementación de las Metas del Desarrollo de las Teorías Cognitivo-Evolutivas desde Habermas y Apel, Ricoeur y Arendt. Tesis para optar al grado de Doctor en Filosofía con mención en Ética, Facultad de Filosofía y Humanidad.

Solomon, M. (2008). Comportamiento del Consumidor: Comprar, Vender y Ser. México: PEARSON Educación.

Soto, C., \& John, P. (2017). Short and Extra-Short Forms of the Big Five Inventory-2: The BFI-2-S and BFI-2-XS. Journal of Research in Personality, 81, 69-81.

Stefani, G. (1987). Comprender la Música. Barcelona: Ediciones Paidós Ibérica.

Takavol, M., \& Dennick, R. (2011). Making sense of Cronbach's alpha. International Journal of Medical Education, 2, 53-55. doi:10.5116/ijme.4dfb.8dfd

Tully, D. (2012). Examining the Relationship between Music Preference and Personality Type. Tesis de licenciatura, DBS School of Arts. Retrieved Febrero 15,2018 , from https://pdfs.semanticscholar.org/db83/915a043fd41f3771693b0bac8b9e2f1047 75.pdf 
Vella, E., \& Mills, G. (2017). Personality, uses of music, and music preference: The influence of openness to experience and extraversion. Psychology of Musica, 45(3), 338-354.

Wang, C. (2015). Do People Purchase What They Viewed from Youtube? : the Influence of Attitude and Perceived Credibility of User-Generated Content on Purchase Intention. Tesis doctoral, Florida State Uiversity, The Graduate School. 


\section{INSTRUMENTO: RELACIÓN ENTRE EL MODELO BIG FIVE DE PERSONALIDAD Y LAS PREFERENCIAS MUSICALES DE ADULTOS RESIDENTES EN LIMA}

\section{Datos generales}

1. Cuántos años tiene: años

2. Sexo:

3. Nivel educativo:
[ ] Universitario
[ ] Bachiller
[ ] Licenciatura
[ ] Maestría

\section{[ ] Masculino [ ] Femenino}

4. Distrito de residencia:

5. ¿En sus ratos de ocio, laboral u otros escucha música?
[ ] Si
[ ] No

\section{Modelo Aplicativo: Big Five}

Aquí hay una serie de opciones que pueden o no aplicar a usted. Por favor escriba un número al lado de cada opción para indicar si está acuerdo o en desacuerdo. A continuación, presentamos una escala de valoración del 1 al 5, donde:
[1] Muy en desacuerdo
[2] Desacuerdo
[3] Indiferente
[4] De acuerdo
(DA)
[5] Muy de acuerdo
(MD)
(DS)
(IND)
(MDA)

\begin{tabular}{|c|l|c|c|c|c|c|}
\hline $\mathbf{N}$ & Soy alguien que... & $\mathbf{1}$ & $\mathbf{2}$ & $\mathbf{3}$ & $\mathbf{4}$ & $\mathbf{5}$ \\
\hline $\mathbf{6 .}$ & Tiende a ser callado. & MD & $\mathbf{D S}$ & $\mathbf{I N D}$ & $\mathbf{D A}$ & $\mathbf{M D A}$ \\
\hline $\mathbf{7 .}$ & Se preocupa por otros, tiene un buen corazón. & 1 & 2 & 3 & 4 & 5 \\
\hline $\mathbf{8 .}$ & Tiende a ser desorganizado. & 1 & 2 & 3 & 4 & 5 \\
\hline $\mathbf{9 .}$ & Se preocupa mucho por las cosas. & 1 & 2 & 3 & 4 & 5 \\
\hline $\mathbf{1 0 .}$ & Se fascina por el arte, música o literatura & 1 & 2 & 3 & 4 & 5 \\
\hline $\mathbf{1 1 .}$ & Es dominante y actúa como líder. & 1 & 2 & 3 & 4 & 5 \\
\hline $\mathbf{1 2 .}$ & Es a veces descortés con los demás. & 1 & 2 & 3 & 4 & 5 \\
\hline $\mathbf{1 3 .}$ & Tiene dificultad para iniciar tareas. & 1 & 2 & 3 & 4 & 5 \\
\hline $\mathbf{1 4 .}$ & Tiende a deprimirse o ponerse triste. & 1 & 2 & 3 & 4 & 5 \\
\hline $\mathbf{1 5 .}$ & Le interesan las ideas concretas y lógicas. & 1 & 2 & 3 & 4 & 5 \\
\hline $\mathbf{1 6 .}$ & Está lleno de energía. & 1 & 2 & 3 & 4 & 5 \\
\hline $\mathbf{1 7 .}$ & Tiende pensar lo mejor de las personas. & 1 & 2 & 3 & 4 & 5 \\
\hline $\mathbf{1 8 .}$ & Es confiable, puede siempre contar conmigo & 1 & 2 & 3 & 4 & 5 \\
\hline $\mathbf{1 9 .}$ & Es emocionalmente estable y no se altera con facilidad. & 1 & 2 & 3 & 4 & 5 \\
\hline $\mathbf{2 0 .}$ & Es original y tiene ideas nuevas. & & 3 & 4 & 5 \\
\hline
\end{tabular}




\section{Opinión sobre las preferencias musicales en la actualidad del público peruano.}

Para las siguientes opciones, indique su nivel de preferencia de los géneros mencionados a continuación. Utilice la escala proporcionada con valoración del 1 al 7 , donde, 1 es desagradable y 7 es agradable:

Desagradable

Ni disgusta / Ni gusta

Agradable

(DS)

(AG)

\begin{tabular}{|c|c|c|c|c|c|c|c|c|}
\hline \multicolumn{2}{|c|}{ Géneros musicales } & $\begin{array}{l}\text { [1] } \\
\text { DS }\end{array}$ & [2] & [3] & [4] & [5] & [6] & $\begin{array}{l}\text { [7] } \\
\text { AG }\end{array}$ \\
\hline 21. & Cumbia & 1 & 2 & 3 & 4 & 5 & 6 & 7 \\
\hline 22. & Salsa & 1 & 2 & 3 & 4 & 5 & 6 & 7 \\
\hline 23. & Huayno & 1 & 2 & 3 & 4 & 5 & 6 & 7 \\
\hline 24. & Electrónica & 1 & 2 & 3 & 4 & 5 & 6 & 7 \\
\hline 25. & Merengue & 1 & 2 & 3 & 4 & 5 & 6 & 7 \\
\hline 26. & Rock & 1 & 2 & 3 & 4 & 5 & 6 & 7 \\
\hline 27. & Reggaetón & 1 & 2 & 3 & 4 & 5 & 6 & 7 \\
\hline 28. & Metal & 1 & 2 & 3 & 4 & 5 & 6 & 7 \\
\hline 29. & Punk & 1 & 2 & 3 & 4 & 5 & 6 & 7 \\
\hline 30. & Baladas & 1 & 2 & 3 & 4 & 5 & 6 & 7 \\
\hline 31. & Chicha & 1 & 2 & 3 & 4 & 5 & 6 & 7 \\
\hline 32. & Criolla & 1 & 2 & 3 & 4 & 5 & 6 & 7 \\
\hline 33. & Bachata & 1 & 2 & 3 & 4 & 5 & 6 & 7 \\
\hline 34. & Pop & 1 & 2 & 3 & 4 & 5 & 6 & 7 \\
\hline 35. & Latin & 1 & 2 & 3 & 4 & 5 & 6 & 7 \\
\hline 36. & Saya & 1 & 2 & 3 & 4 & 5 & 6 & 7 \\
\hline 37. & Festejo & 1 & 2 & 3 & 4 & 5 & 6 & 7 \\
\hline 38. & Hip Hop / Rap & 1 & 2 & 3 & 4 & 5 & 6 & 7 \\
\hline 39. & Blue & 1 & 2 & 3 & 4 & 5 & 6 & 7 \\
\hline 40. & Jazz & 1 & 2 & 3 & 4 & 5 & 6 & 7 \\
\hline 41. & Trova & 1 & 2 & 3 & 4 & 5 & 6 & 7 \\
\hline
\end{tabular}




\begin{tabular}{|c|c|c|c|c|c|}
\hline Problema & Objetivo & Hipótesis & Variables & Indicadores & Método \\
\hline $\begin{array}{l}\text { Problema General } \\
\text { ¿Cuál es la relación entre el } \\
\text { Modelo Big Five de } \\
\text { personalidad y las preferencias } \\
\text { musicales de adultos residentes } \\
\text { en Lima? } \\
\text { Problema secundario } \\
\text { 1. ¿El Modelo Big Five de } \\
\text { Personalidad influenciado por el género? } \\
\text { 2. ¿Las preferencias musicales } \\
\text { de los adultos residentes en } \\
\text { Lima son influenciadas por } \\
\text { la edad? } \\
\text { 3. } \\
\text { Pel Modelo Big Five de } \\
\text { influenciado por la edad? }\end{array}$ & $\begin{array}{l}\text { Objetivo General } \\
\text { Conocer la relación entre el } \\
\text { Modelo Big Five de } \\
\text { Personalidad y las } \\
\text { preferencias musicales de } \\
\text { adultos residentes en Lima } \\
\text { Objetivo Secundario } \\
\text { O1: Determinar si el Modelo } \\
\text { Big Five de Personalidad es } \\
\text { influenciado por el género. } \\
\text { O2: Determinar si las } \\
\text { preferencias musicales de } \\
\text { los adultos residentes en } \\
\text { Lima son influenciadas por la } \\
\text { edad } \\
\text { O3: Determinar si el Modelo } \\
\text { Big Five de Personalidad es } \\
\text { influenciado por la edad. }\end{array}$ & $\begin{array}{l}\text { Hipótesis general: } \\
\text { H: Si hay relación entre el } \\
\text { Modelo Big Five de } \\
\text { Personalidad y las } \\
\text { preferencias musicales en } \\
\text { adultos residentes en Lima. } \\
\text { Hipótesis Secundaria } \\
\text { H1: El Modelo Big Five de } \\
\text { Personalidad si es } \\
\text { influenciado por el género. } \\
\text { H2: Las preferencias } \\
\text { musicales de los adultos } \\
\text { residentes en Lima son } \\
\text { influenciadas por la edad. } \\
\text { H3: El Modelo Big Five de } \\
\text { Personalidad sí es } \\
\text { influenciado por la edad. }\end{array}$ & $\begin{array}{l}\text { Variable independiente: } \\
\text { Modelo Big Five de } \\
\text { Personalidad } \\
\text { Variables dependientes: } \\
\text { Preferencias musicales de } \\
\text { adultos residentes en Lima. }\end{array}$ & $\begin{array}{l}\text {-Nivel de } \\
\text { preferencia por } \\
\text { cincor géneros } \\
\text { musicales } \\
\text { - Festejo } \\
\text {-Cumbia } \\
\text {-Rock } \\
\text {-Salsa } \\
\text {-Reggaetón }\end{array}$ & $\begin{array}{l}\text { Diseño: } \\
\text {-Correlacional } \\
\text {-No experimental } \\
\text {-Transversal } \\
\text {-Descriptiva } \\
\text { Pruebas estadísticas } \\
\text { - Prueba de } \\
\text { correlación de (Rho } \\
\text { deSperman) } \\
\text { - Prueba de Mann } \\
\text { Whitney } \\
\text { Nivel de significancia } \\
0.05 .\end{array}$ \\
\hline
\end{tabular}


Anexo 3: Entrevista a especialista

Datos del entrevistado: José Luis Valverde López, musico profesional y director. Es miembro del claustro universitarios de la Universidad San Ignacio de Loyola

E: Cuéntenos un poco sobre su experiencia en la música

J: Tengo 42 años de experiencia en la música. Estudié en Estados Unidos desde niño y fui destacado en el ámbito de canto y del piano en California. Después regresé a Perú y estudié en un colegio nacional porque mi año escolar no era compatible con Estados Unidos, después tuve clases personales de piano y entre inmediatamente ese año a una iglesia llamada San Francisco de Asís de Barranco. Ingresé a un coro, pero no tenían técnica musical ni armonía, aunque era un grupo social muy alegre y muy divertido, pero tuve la oportunidad de conocer a un sacerdote que me invito a aprender con él y cantar. Entraba a las misas de los difuntos de lunes a viernes a cantar desde que tenía 13 años hasta los 16 años.

E: ¿Cuándo vio el tema profesional sobre la música que ya estaba inculcado en usted?

J: Lo que sucede es que no tenía planeado ser un profesional en la música, yo quería ser un periodista. Pese a que estudie periodismo y esa era mi proyección, pero al mismo tiempo siendo músico. La música para mí era un tema muy bonito, pero yo nunca supuse que podía ser llevado a otro nivel. A los 16 años en un colegio había que organizar una orquesta al estilo Rulli Rendo que era la época de ese momento en el año 1975. Empecé trabajando cargando equipos de sonido, empezando con la parte más dura a un sector bastante privilegiado en ese año. Lo cual era un privilegio ya que si quieres entrar tenías que ser muy bueno o ser bastante profesional. De esa manera me "cachuelaba" ya que me había quedado huérfano de padre y madre y tenía que pagarme mis estudios. Estudiaba periodismo y trabaja al mismo tiempo. En uno de ese momento se presentó una oportunidad de cantar en una de las mejores orquestas en ese tiempo y entro al mundo de la música de hacer coros a pasar a un estudio de grabación y ahí en ese tiempo se grababan los discos. La industria disquera en ese tiempo no era con copias reales de los propios autores; es decir, los Beatles querían publicar su música acá y no la podían publicar. Tenían que grabar acá a alguien que hiciera los Beattles y publicarlos acá. Esa era el negocio en ese entonces de la música. Quienes manejaban los estudios más grandes del Perú, el negocio era que ellos mismos fabricaban sus discos. Tenían las máquinas para hacer los discos y 
se vendían un millón y daba mucho dinero y contrataban los músicos peruanos para hacerlo. Entonces entre a ese mundo de la grabación a grabar coros, después como solista. Tengo cientos de discos grabados con mi voz y en la publicidad tengo 15 años de experiencia me dedique a grabar comerciales y voz de comerciales para distintos estudios de grabación.

E: ¿Qué opina de la música en sí y de los consumidores peruanos?

J: El consumidor peruano ha perdido el estrato de la música, hoy en día no se consume, se piratea. Entonces, si bien es cierto que ahora los libros son virtuales y considero que eso haría que la industria de los libros físicos morirá. Actualmente, el tema de piratería es muy fuerte, incluso yo consumo piratería, ya que al principio compraba películas originales, pero era demasiado caro.

E: ¿Hoy en día crees que el consumidor peruano escucha más música que antes?

La mayoría de los peruanos adultos escucha música bailable clásica. Para mí el peruano adulta escucha el $90 \%$ de música "clásica" y el 10\% moderna. Para mí el nivel de creatividad anterior es muy superior al nivel actual, en Sudamérica. Los músicos actualmente ya no crean acá y optan por crear afuera. Es ahí cuando llegamos a los nuevos géneros y comienzan a hacer más fácil la música, creyendo que es música, pero no es música. Ahí está el tema contraproducente. Cuando se hace un jingle, tú puedes rapear, pero no has hecho música, no has usado tan siquiera una nota musical. Han puesto solamente percusiones, entonces no hay un arreglo musical, no hay un género. Entonces ahí existe una confusión en el término de la música en general.

E: ¿Crees que hoy en día en consumidor peruano usa más los celulares que el disco?

J: Claro que sí, el Spotify lidera es el más rankeado en el mundo. David Stopps en un seminario organizado por INDECOPI señalo que "Hoy los medios digitales son el camino para vender música". El tema es que en Perú actualmente no se encuentra una fórmula que sea propia.

E: ¿Entonces usted cree que el Marketing puede ayudar a la música?

J: Si siempre. Yo he sido productor por 15 años de los eventos más grandes no existió ningún momento donde yo no puse música desde la puerta. La música es algo que rima, yo por ejemplo tengo un comercial que dice marca 1977. El tema comercial lo dirigen más a un tema visual cuando la parte visual ya está gastada. En el canal 4 yo fui gerente de producción musical y se tenía que colocar de acuerdo a su criterio 
la música incidental para las novelas. Es un tema donde las universidades adolecen porque no hay ninguna universidad que encante y cree una moda

E: Existen estudios acerca de las preferencias musicales y el segmento de residentes de Lima y similares. ¿Qué piensa sobre ello?

J: Esa información es bien sabida. La información sobre cuál es el tema más escuchado, que música se escucha más en la mañana, tarde o noche, genero de preferencia o que es lo que escucha más en las radios.

E: ¿Géneros musicales existen varios, pero que criterios consideras adecuados para seleccionar una serie de estos y que tengan correlación con los elementos de la personalidad para los adultos?

J: La salsa, a pesar que no es consumida en el sentido de que yo la compro. Solamente la utilizo cuando bailo significa que lo hago cuando hay una acción. Cuando yo pongo algo en acción y el tema está muy bien seleccionado porque posee los factores de sentimiento, emoción, letra de una serie de cosas. Una música tiene que moverte, traerte recuerdos y hay muchas cosas que hacen posible esto.

E: A continuación, te mostrare una lista de géneros musicales que según GFK tiene cierta preferencia por los adultos limeños ¿Usted me podría indicar cinco géneros que están de moda para usted?

J: Salsa, cumbia, rock y el festejo.

E: ¿En tema que es de moda para los chicos de 18 años a 24 años considera el reggaetón?

J: Para un tema comercial, el reggaetón lo es. En el reggaetón no hay notas, no hay posibilidad de distinción. En cambio, en lo demás todo se puede variar, o se puede transformar. En el reggaetón no hay poder de transformación. La transformación está en la fusión. En mi opinión un tema que se está viniendo con mucha fuerza es la salsa. El Perú es un buen país medidor al igual que el Ecuador. La cumbia que es un género que después que la música criolla, ha tenido un auge en el Perú, es un género que más se ha vendido. Radio exitosa es multimillonaria por la Cumbia. Ellos compran el producto, lo utilizan, lo transforman y este es su dominio en el mercando. Entonces no puedes ganar porque no se puede hacer un negocio en medio de un tema complicado. Por ejemplo, la canción "el embrujo" fue registrado y hecho por una persona y si uno lo utiliza se tiene que seguir pagando una serie de gastos y costos y 
sobrecostos inmensos. Es más barato mandar a crear una canción y pagar los derechos de autor y que se compre para uno mismo.

E: ¿Entonces, usted considera que, para hacer un estudio de personalidad, música y un poco de marketing? Los tres básicos vendrían a ser salsa, rock y cumbia. ¿En un aspecto más moderno se puede hablar de reggaetón o la música electrónica?

J: Todas esas fusiones son incidentes, porque para un tema comercial se utilizan. A la universidad le comuniqué que hice unas partituras que están plantadas de 10 arreglos musicales y para hacer el disco cuesta \$150 000 USD. Son 10 mixes instrumentales que tienen sonidos instrumentales y estos mixes tienen criollo, reggaetón, la historia de cada país, el cual se puedes colocar en una universidad y cuenta con una serie de ítems que le da fuerza. Por ejemplo, existen universidades que escogen un tema contagioso de reggaetón para publicitarse y creen que será usado siempre. Solo se utilizó para una campaña y eso es lo que la publicidad ha perdido. La publicidad ganaba porque la campaña se repetía 10 años. En cañal 5 usaba su propia cuña de musical por 15 años. Todas estas recomposiciones marean lo que tiene que hacer uno es tomar un tema y casarse con ese tema. Yo hice un tema para el canal 4 para su aniversario y el tema pego por cuatro años y pegaba en las fiestas porque reunió la estrategia. El verdadero producto es quien amarra todo para reunir la estrategia. Un tema que me apena es que en Perú es el único sitio donde se detesta la música criolla y eso es abominable. Los que crean la música criolla es gente ignorante, pero tienen un "feeling", su composición es igual al de un libro pues se trata sobre una experiencia. Entonces, aquí hay un tema, si uno quiere identificar una universidad con algo hay que hacerlo con algo que se pueda tener. La habilidad está en la publicidad. Yo trabajé en Disney por 5 años en el área de creatividad y consistía en que teníamos definir todos nuestros temas creativos de un tema. Yo no estoy de acuerdo con marketing para nada, lo que sí creo que hay cosas que desconocía, lo que sí creo y aprendí es encontrar túneles que lleguen más rápido, pero puede existir 100000 personales, pero cuantos te pueden comprar ¿10?. Cuando el marketing puede dirigirse de otra forma.

E: Muchas gracias por su participación. 
Anexo 4: Presentación de resultados publicado en revista internacional donde se usa Rho de Spearman para los componentes de personalidad y preferencias musicales

\begin{tabular}{|c|c|c|c|c|c|c|}
\hline \multirow[t]{2}{*}{ Musical dimensions } & \multirow[t]{2}{*}{ Statistics } & \multicolumn{5}{|c|}{ Personality } \\
\hline & & E & A & c & ES & 1 \\
\hline \multirow[t]{2}{*}{ Crassical and Etrnic Music } & tho & 0.c68: & 0,028 & $0.135 *+1$ & $0.108^{2+1}$ & $0.232+1$ \\
\hline & $D$ & 0027 & 0386 & 0,000 & 0.000 & 0.000 \\
\hline \multirow[t]{2}{*}{ Rock Music } & tho & $-0,000$ & $-0.075^{\circ}$ & $-0.148^{*+1}$ & $-00096^{\circ+}$ & $0.137 *+1$ \\
\hline & $\rho$ & 0,283 & 0.021 & 0.000 & 0.008 & 0.000 \\
\hline \multirow[t]{2}{*}{ Brazilan Marstreom Music } & Fino & $0.204^{2 *}$ & Doges" & 0,042 & 0,052 & $-0100^{\circ}$ \\
\hline & $\rho$ & 0,000 & $0,02 B$ & D.168 & 0,083 & Doot: \\
\hline \multirow[t]{2}{*}{ Imen Darice Mtis: } & tho & $0.179=$ & Donger & $0.168+1$ & D.tagen & $0,097 *$ \\
\hline & $o$ & 0.000 & 0.025 & 0000 & 0000 & 0.002 \\
\hline \multirow[t]{2}{*}{ Brazlan Musco } & tho & $0.1 \mathrm{Bg}$ & $0.130^{20+}$ & $a+33=$ & $0.145^{20+2}$ & $0.088 *$ \\
\hline & $D$ & 0.000 & 0.000 & 0.000 & 0.000 & 0.004 \\
\hline \multirow{2}{*}{ Eecteoric Music } & tho & $0.091+$ & 0.004 & 0.007 & -0.045 & $0.091=$ \\
\hline & D & 0.000 & 0.904 & 0.928 & 0.147 & 0003 \\
\hline \multirow[t]{2}{*}{ American Music } & tho & $0.131 \cdots$ & 0.050 & $-0,048$ & $0.070^{\circ}$ & $0,168^{1+4}$ \\
\hline & D & 0.000 & 0.104 & 0.121 & 0.024 & 0.000 \\
\hline \multirow[t]{2}{*}{ Aherrative Music } & fino & 0.023 & 0.001 & $-0.173+4$ & $-0.071^{+}$ & $0.130^{14}$ \\
\hline & $p$ & 0,463 & 09677 & 20000 & 0,022 & 0000 \\
\hline \multirow[t]{2}{*}{ Afro-American Musis } & Fono & 0.139 & -0.013 & $-0.090^{\circ *}$ & 0.030 & -0.018 \\
\hline & D & 0,000 & 0,732 & 0.004 & 0.328 & 0.567 \\
\hline
\end{tabular}

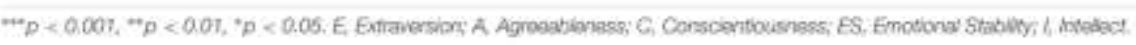

Fuente: Herrera, Soares-Quadros, \& Lorenzo (2018)

Figura 13: Versión de los resultados de Herrera, Soares-Quadros, \& Lorenzo (2018) para el caso de ciudadanos de Brasil 
Anexo 5: Presentación de resultados publicado en revista internacional donde se usa análisis descriptivo y correlacional para las preferencias musicales y el genero

Preference ratings for music genres

\begin{tabular}{|c|c|c|c|}
\hline & Overall & Males & Females \\
\hline \multicolumn{4}{|c|}{ Pop $6.03(1.17) 5.72(1.22) 6.49(0.93)^{* * *}$} \\
\hline \multicolumn{4}{|c|}{ Rock $5.41(1.46) 5.36(1.48) 5.46(1.45)$} \\
\hline \multicolumn{4}{|c|}{ Classical 5.26 (1.14) $5.03(1.10) 5.57(1.13)^{* * *}$} \\
\hline \multicolumn{4}{|c|}{ Jazz $5.01(1.26) 4.71(1.20) 5.40(1.23)^{* * *}$} \\
\hline \multicolumn{4}{|c|}{ Soul $4.98(1.43) 4.80(1.53) 5.21(1.27)^{*}$} \\
\hline \multicolumn{4}{|c|}{ Rap 4.65 (1.81) 4.69 (1.86) 4.60 (1.75) } \\
\hline \multicolumn{4}{|c|}{ Gospel $4.57(1.34) 4.40(1.27) 4.81(1.32)^{*}$} \\
\hline \multicolumn{4}{|c|}{ Reggae 4.27 (1.66) 4.25 (1.75) 4.29 (1.55) } \\
\hline \multicolumn{4}{|c|}{ Punk 4.15 (1.58) 4.29 (1.53) 3.98 (1.63) } \\
\hline \multicolumn{4}{|c|}{ Opera $4.08(1.27) 3.76(1.28) 4.46(1.15)^{* * * *}$} \\
\hline \multicolumn{4}{|c|}{ Enka $\quad 3.56(1.32) 3.40(1.32) 3.77(1.29)^{*}$} \\
\hline \multicolumn{4}{|c|}{ Metal 3.19 (1.77) $3.31(1.84) 3.07$ (1.62) } \\
\hline
\end{tabular}

Fuente: Brown (2012)

Figura 14: Versión de los resultados de Brown (2012) para el caso de estudiantes japoneses.

Nota: En el caso de la investigación de residentes adultos en Lima fue empleada el MannWhitney, dado que las variables no tienen distribución normal. 
Anexo 6: Presentación de resultados publicado en revista internacional donde se usa análisis correlacional entre el rango de edad y las preferencias musicales

\begin{tabular}{|c|c|c|c|c|c|c|c|c|c|c|c|c|c|c|c|}
\hline & \multicolumn{3}{|c|}{ Openneas } & \multicolumn{3}{|c|}{ Conscientiousness } & \multicolumn{3}{|c|}{ Extraversion } & \multicolumn{3}{|c|}{ Agreeableness } & \multicolumn{3}{|c|}{ Neuroticiam } \\
\hline & $12-19$ & $20-39$ & $40-65$ & $12 \cdot 19$ & $20-30$ & $40-65$ & $12-19$ & $20-39$ & $40-65$ & $12-19$ & $20-30$ & 40.65 & $12 \cdot 19$ & $20-39$ & $40-65$ \\
\hline RAB & .019 &,- 004 & .053 & $05 b$ & .000 & 150 & .106 & .665 & 326 & -049 & ant & 326 & 027 & -1001 & 175 \\
\hline Rap & -019 & .011 & -205 & -085 & -.065 & A50 & eso & 108 & 052 & -.076 & 062 & .052 & .003 & $-m / 2$ & -158 \\
\hline Electronic & 1246 & .106 & -138 & -043 & -031 & 152 & ots & 638 & -246 & -000 & -050 & -246 & .056 & -023 & 183 \\
\hline Rock & -.075 & -104 & .095 & 058 & .916 & -124 & -085 & -102 & -182 & 970 & -031 & -182 & .014 & 053 & .182 \\
\hline New Age & 142 & .105 & 133 & 097 & -053 & 006 & -1022 & $\Rightarrow 134$ & -209 & .008 & 911 & -.200 & -1062 & -064 & 103 \\
\hline Classical & .050 & .008 & 206 & 028 & -.060 & 261 & -.136 & -.146 & -136 & $-\infty 70$ & -010 & -136 & -015 & -.005 & -1050 \\
\hline Reggae & -.615 & 846 & .185 & .102 & -059 & -050 & 099 & .025 & 046 & $-a 3 z$ & .5s & .046 & 028 & -802 & -138 \\
\hline Blues & 130 & .167 & .358 & -048 & -.046 & 321 & 060 & 032 & 252 & -006 & ots & 252 &,- 054 & -005 & -.552 \\
\hline Country & .117 & .126 & 325 & -067 & -073 & 154 & 005 & .005 & .128 & 062 & .184 & 128 & .049 & $-02 \pi$ & -109 \\
\hline World & .114 & 217 & 201 & -016 & -.009 & 217 & -102 & -1054 & 028 & -056 & -025 & ans & 061 & -.014 & -336 \\
\hline Folk & 230 & 231 & 368 & .014 & $\$ 114$ & -268 & 066 & -860 & 181 & .101 & .110 & 181 & .064 & 004 & -217 \\
\hline $\begin{array}{l}\text { Easy } \\
\text { Listening }\end{array}$ & cost & .060 & -.161 & 020 & .024 & 256 & an1 & ser & 212 & . & onI & 212 & 035 & -.012 & 006 \\
\hline Jan & 139 & 106 & -.124 & -0.47 & -0.05 & 510 & .005 & -.010 & .062 & -053 & -068 & .062 & -0.00 & .004 & -106 \\
\hline $\begin{array}{l}\text { Vocal (a } \\
\text { cappella) }\end{array}$ & .132 & .170 & 282 & 059 & -.007 & 125 & ess & .013 & 136 & -074 & -001 & 136 & -014 & .002 & -091 \\
\hline Punk & -.032 &,- 008 & 089 & 130 & $=103$ & n81 & -111 & -029 & -974 & .905 & 006 & -.974 & .101 & ate 4 & 220 \\
\hline Alternative & 131 & 116 & .154 & -108 & -165 & .507 & -010 & $-.05 z$ & -027 & ors & 029 & -027 & .229 & 137 & ตาอ \\
\hline Pop & 621 & 000 & -.157 & ous & .005 & 052 & 064 & อ17 & 287 & .017 & 194 & 287 & oto & -010 & -275 \\
\hline $\begin{array}{l}\text { Heavy } \\
\text { Metal }\end{array}$ & -.033 &,- 044 & -.117 & -005 & -.012 & 1038 &,- 148 & -126 & -339 & -.058 &,- 105 & -335 & -1930 & -050 & 372 \\
\hline
\end{tabular}

Fuente: Ferwerda, Schedl, Tkalcic (2017). 


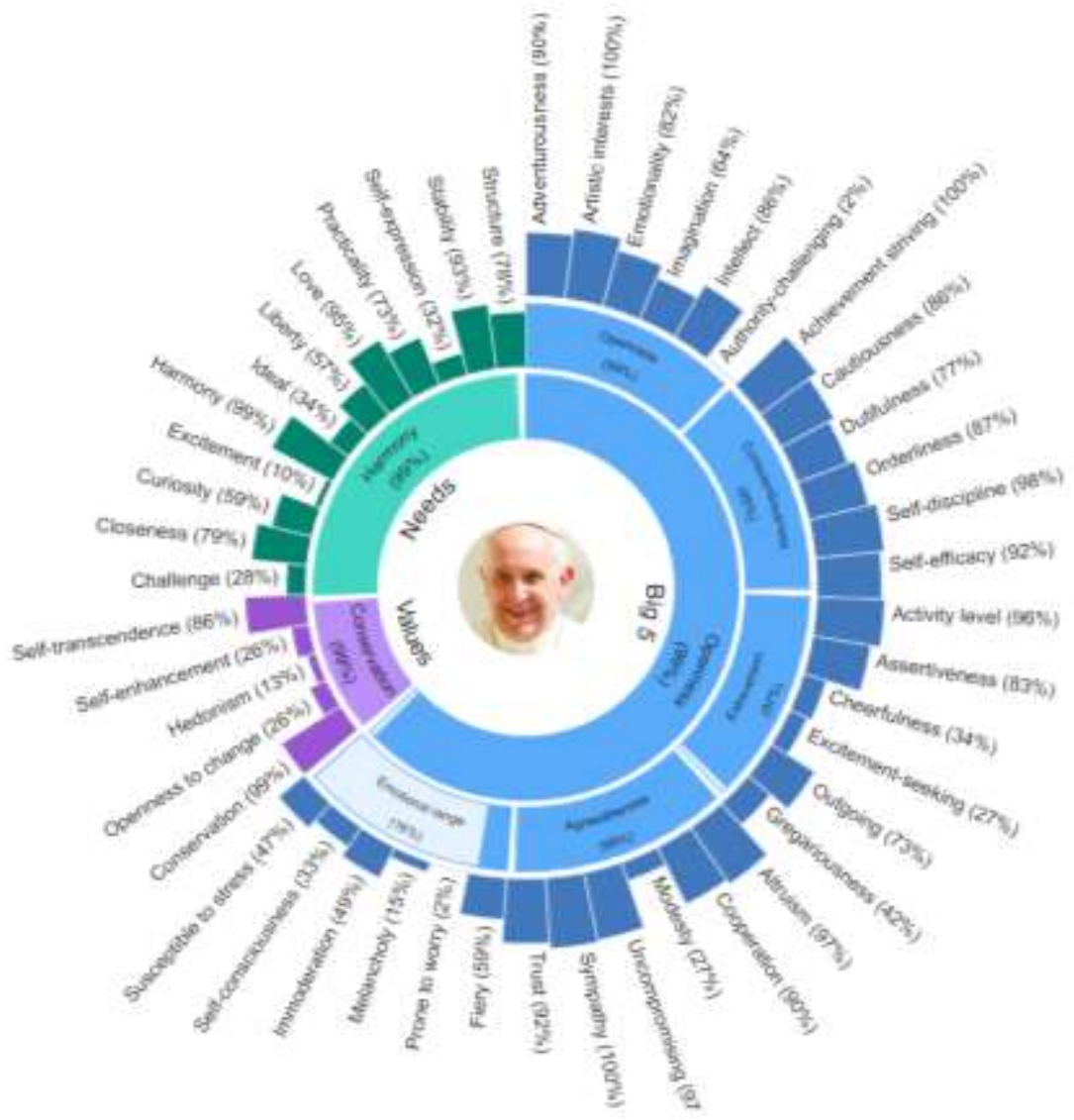

Figura 15: Versión computarizada el Modelo Big Five de personalidad aplicada a la cuenta en Twitter del Papa Francisco

Fuente: IBM (2019) 